\title{
NuEVOS DATOS PARA LA CARACTERIZACIÓN MATERIAL DE LA TRANSICIÓN BRONCE Final - Hierro I y Hierro I en Alarcos (Poblete, Ciudad Real)
}

Material characterization of the transition Late Bronze Age - Early Iron Age and Early Iron Age levels of Alarcos (Poblete, Ciudad Real)

\section{PEDRO MIGUEL NARANJO}

Dpto.de Historia. Universidad de Castilla-La-Mancha.pedro_n90@hotmail.com

RESUMEN:

En este artículo se estudian de forma exhaustiva los materiales arqueológicos exhumados en los niveles del Bronce Final-Hierro I y Hierro I en el Sector III de Alarcos (Poblete-Ciudad Real, Ciudad Real) durante la campaña de 2017, un conjunto fundamentalmente cerámico que ofrece una importante información para la caracterización material de estas fases culturales en el Alto Guadiana. Las características de los materiales permiten plantear la inclusión de Alarcos en la órbita de influencia de la cultura tartésica que durante este periodo estaba experimentando un importante desarrollo cultural.

Palabras clave: Alto Guadiana, cerámica, tipología, Tarteso.

Abstract:

In this paper, I study the archaeological materials found in the Late Bronze Age-Iron Age and Iron Age levels in Sector III from Alarcos (Poblete-Ciudad Real, Ciudad Real) during 2017, fundamentally ceramic materials that offer important information for the material characterization of the transitional period between the Late Bronze Age and the Iron Age and Iron Age in the Upper Guadiana. The characteristic of the pottery allows to consider the inclusion of Alarcos in the influence of the Tartessian culture, which it had an important cultural development during this period.

Key words: Upper Guadiana, pottery, typology, Tartessos. 


\section{LOCALIZACIÓN DEL YACIMIENTO, OBJETIVOS Y METODOLOGÍA}

El yacimiento arqueológico de Alarcos (Poblete-Ciudad Real, Ciudad Real) se sitúa en la orilla izquierda del río Guadiana, a una altura de $654 \mathrm{~m}$ sobre el nivel del mar y a unos $100 \mathrm{~m}$ sobre el valle (fig. 1). Su privilegiada posición en altura le permitió una defensa natural y el control visual de un territorio circundado por fértiles llanos, aptos para las actividades agropecuarias, aunque también controló las rutas comerciales que unían la meseta $\mathrm{N}$ con el SO peninsular.

Según la documentación actual, el enclave presenta una ocupación desde la transición Bronce Final-Hierro I hasta época medieval, pasando por una importante fase íbera (García Huerta et al. 2018; 2020).

Los primeros testimonios conocidos sobre el Bronce Final-Hierro I y Hierro I en Alarcos se localizaron en posición secundaria debido a las alteraciones ocasionadas por las posteriores construcciones íberas y medievales (García Huerta y Fernández Rodríguez 2000). Adscritas a estas fases, se publicaron las tumbas 1 y 4 del Sector IV-E en las que se hallaron un cuenco pintado estilo Medellín y un vaso bicónico con incrustaciones metálicas, empleados como urnas cinerarias (Fernández Rodríguez 2001). También se realizó el corte C-23 en el Sector IV del que se obtuvieron las primeras fechas radiocarbónicas relativas a estas etapas y algunos materiales in situ, aunque escasos y muy fragmentados (Fernández Rodríguez 2012).

En los últimos años se ha podido avanzar en el conocimiento de estas etapas en Alarcos gracias a los trabajos sistemáticos realizados por la Universidad de Castilla-La Mancha en el Sector III (García Huerta y Morales 2017; García Huerta 2019). En estas intervenciones se han constatado varias estructuras, como agujeros de poste, algunos hogares y dos habitaciones interpretadas como cabañas, una de ellas de planta circular. La publicación de estas estructuras ha venido acompañada por los materiales asociados, mayoritariamente cerámica realizada a mano y decorada con múltiples técnicas: pintura, mamelones, incisiones, ungulaciones, etc.

Los últimos trabajos realizados en el Sector III sobre niveles correspondientes a estos periodos se desarrollaron durante 2017 y 2018, cuyas estructuras, estratigrafía y algunos materiales han sido publicados recientemente (García Huerta et al. 2020). Dicha publicación nos permite prescindir del estudio estratigráfico y arquitectónico para centrar la atención en el estudio exhaustivo de los materiales inéditos exhumados en 2017, ya que los relativos a 2018 se encuentran en fase de estudio. De este análisis se exceptúan las cerámicas a mano pintadas al haber sido publicadas recientemente (Miguel 2020). A grandes rasgos, la excavación arqueológica durante la campaña de 2017 se centró en los niveles situados por debajo de la cabaña circular anteriormente citada. La zona intervenida se dividió en dos zonas (U18-3, U18-2), diferenciándose en la U18-3 cinco niveles arqueológicos (U18-3-1, U18-3-2, U18-3-3, U18-3-4, U18-3-5) y otros cinco en la U18-2 (U18-2-1, U18-2-2, U18-2-3, U18-2-4, U18-2-5), además de dos interfaces en esta última zona (U18-2-2/3, U18-2-3/4). Todos estos niveles se caracterizan por presentar una escasa compacidad y contener mucha materia orgánica, como carbones, cenizas y fauna que se asocian a la gran cantidad de cerámicas estudiadas en este trabajo. Estos estratos, algunos con una potencia máxima de $40 \mathrm{~cm}$, oscilan entre el negro y el marrón oscuro, contrastando con los suelos de tierra clara y apisonada de unos $2 \mathrm{~cm}$ de potencia que definen las interfaces en la U18-2 y algunos niveles de la U183. Todos los materiales muestran homogeneidad tipológica evidenciando su adscripción a una misma fase cultural.

La relevancia de este trabajo radica en el gran desconocimiento que actualmente se tiene sobre la cultura material de las comunidades que poblaron el Alto Guadiana durante estas fases protohistóricas, debido fundamentalmente a la escasez de yacimientos excavados de esta época y a la ausencia de restos arqueológicos estratificados que permitan establecer cronologías, seriaciones cerámicas o interpretaciones sobre los usos por asociación de materiales. Así, tan sólo se cuenta en la actualidad con los materiales del nivel 13 de la Bienvenida-Sisapo (Fernández Ochoa et al. 1994; Zarzalejos et al. 2012) y los de los niveles 1 y 2 del C-23 de Alarcos (Fernández Rodríguez 2012: 60), además de algunos niveles tanto del Sector III de este último (García Huerta y Morales 2017) como del Cerro de Las Cabezas (Esteban et al. 2003), como referentes para la sistematización material de la transición Bronce Final-Hierro I en el Alto Guadiana.

Por su parte, el Hierro I queda representado por los niveles 11-12 del Corte A1 (ab) y el edificio del Área 4 de La Bienvenida-Sisapo (Fernández Ochoa et al. 1994: 144-145; Zarzalejos et al. 2017), Villanueva de la Fuente-Mentesa Oretana (Benítez de Lugo 2004), los niveles inferiores del Cerro de las Cabezas, bien fechados por una fíbula de doble resorte (Vélez y Pérez Avilés 1999), los niveles 3 y 4 del C-23 (Fernández Rodríguez 2012: 60) y otros del Sector III de Alarcos (García Huerta y 


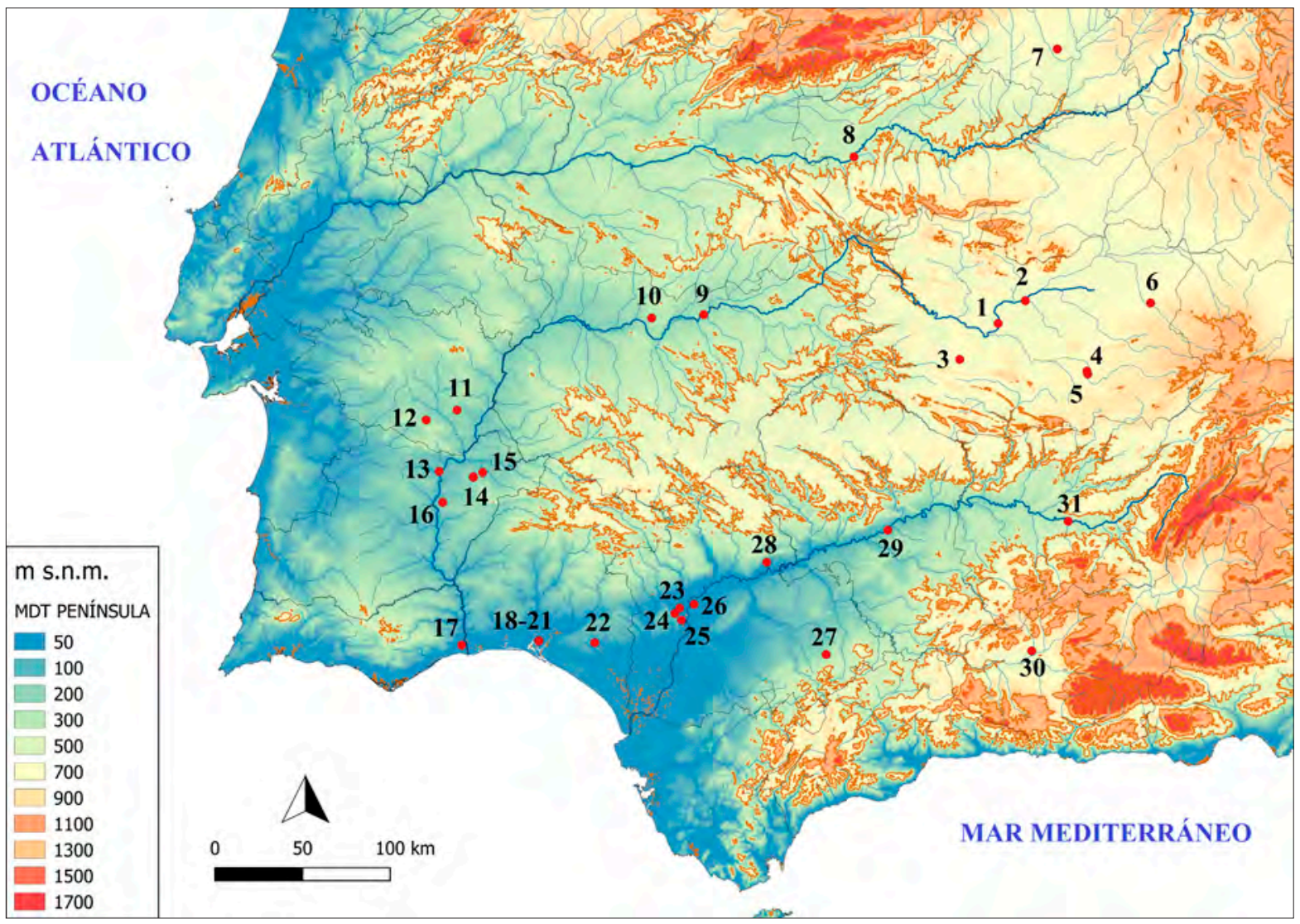

Fig. 1: Mapa de la península ibérica con los yacimientos citados en el texto: 1. Alarcos (Poblete-Ciudad Real, Ciudad Real); 2. Calatrava la Vieja (Carrión de Calatrava, Ciudad Real); 3. La Bienvenida-Sisapo (Almodóvar del Campo, Ciudad Real); 4. Cerro de las Cabezas (Valdepeñas, Ciudad Real); 5. Casa de Rana (Valdepeñas, Ciudad Real); 6. Peñarroya (Argamasilla de Alba, Ciudad Real); 7. Cerro de San Antonio (Madrid); 8. Tumba de El Carpio (Belvís de la Jara, Toledo); 9. Medellín (Badajoz); 10. Escuela de Hostelería (Mérida, Badajoz); 11. Rocha do Vigio 2 (Reguengos de Monsaraz, Alentejo); 12. Monte do Bolor 3 (São Brissos, Beja); 13. Poço Novo 1 (Barros de Beja, Beja); 14. Torre Velha 3 (Serpa); 15. Cabeço Redondo (Sobral da Adiça, Moura); 16. Salsa 3 (Serpa); 17. Castro Marim (Faro, Algarve); 18. Méndez Núñez 7-13/Plaza de las Monjas 12 (Huelva); 19. Cabezo de San Pedro (Huelva); 20. La Joya (Huelva); 21. La Piterilla (Huelva); 22. San Bartolomé (Almonte, Huelva); 23. Jardín de Alá (Salteras, Sevilla); 24. Cerro de la Cabeza (Valencina de la Concepción, Sevilla); 25. El Carambolo (Camas, Sevilla); 26. Cerro Macareno (La Rinconada, Sevilla); 27. Cuesta de los Cipreses (Osuna, Sevilla); 28. Mesa de Setefilla (Lora del Río, Sevilla); 29. Colina de los Quemados (Córdoba); 30. Cerro de los Infantes (Pinos Puente, Granada); 31. Cerro del Viento (Puente del Obispo, Baeza, Jaén).

Morales 2017) y las estructuras de Peñarroya (García Huerta et al. 1999) o los niveles inferiores del A-16 de Calatrava la Vieja (Miguel 2019), los dos últimos casos de un momento avanzado.

Los materiales estratificados de estos yacimientos, especialmente los del corte A1 (ab) de la Bienvenida-Sisapo, han sido de referencia para secuenciar estas fases culturales en el Alto Guadiana, sirviendo de guía para la ubicación cronológica y cultural de los materiales descontextualizados de Calatrava la Vieja (Miguel 2019) y otros hallados en niveles superficiales o en prospecciones (Zarzalejos et al. 2012).
De esta forma, en el actual estado de la investigación, los datos que proporcionan los materiales en posición primaria de Alarcos revisten el máximo interés, sobre todo si se tiene en cuenta su asociación a muestras analizadas por C-14, ofreciendo una cronología calibrada que, hasta la actualidad y en el contexto del Alto Guadiana de la primera mitad del Primer milenio a.C., se restringe a la información de Alarcos.

En cuanto a la metodología, los materiales se han clasificado en cerámica, lítica y metal. La cerámica constituye, con gran diferencia, el material arqueológico más abundante. Para su estudio se ha distinguido entre las 
formas y las decoraciones, agrupando los recipientes, en función de su perfil y relación diámetro/profundidad, en cazuelas, fuentes, cuencos, platos, vasos esferoides y elipsoides y soportes de carrete. En un apartado dentro de la cerámica se han diferenciado los objetos cerámicos que no constituyen un recipiente, como las fichas y las pesas de telar. Dentro de cada grupo, y tras el estudio de sus características técnicas, se han determinado tipos. Para su denominación se han empleado las distintas tipologías al uso en la investigación, como la de Ruiz Mata (1995) y la de González de Canales et al. (2010) para las formas del SO, la de González Prats (1983) para el levante o la de Blasco et al. (1991) para los vasos característicos de la meseta.

\section{ESTUDIO DE LOS MATERIALES ARQUEOLÓ- GICOS}

\section{CERÁMICA}

El material cerámico exhumado durante la campaña de 2017 está elaborado a mano en su totalidad.

\section{LAS FORMAS}

Algunas de las formas registradas en 2017 ya se conocían, pues gran parte de la zona intervenida (U18-2) corresponde, en realidad, a los niveles inferiores de la mitad de la estructura circular anteriormente referida. $\mathrm{La}$ otra mitad restante ya fue excavada en campañas anteriores, lo cual explica que muchas de las piezas de 2017 pegaran con otras de 2013, como alguna cazuela de carena alta (fig. 3,2 ) o el vaso à chardon con decoración incisa (fig. 9, 11; García Huerta y Morales 2017: fig. 6). Esta circunstancia también explica las semejanzas entre

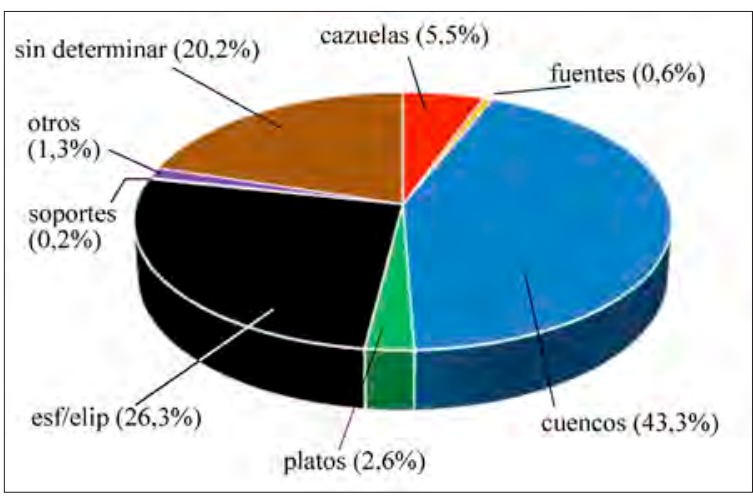

Fig. 2: Proporción de las formas documentadas en 2017. todas las fechas radiocarbónicas obtenidas (García Huerta et al. 2020: tabla 12).

Como se puede observar en la proporción total del material cerámico típico exhumado durante la campaña de 2017 (fig. 2), correspondiente a 529 fragmentos (número mínimo de individuos), son predominantes los cuencos $(43,3 \%)$, seguido de los recipientes esferoides y elipsoides $(26,3 \%)$. Las cazuelas $(5,5 \%)$ y los platos $(2,6 \%)$, en cambio, presentan escasas proporciones, mientras que las fuentes y los soportes de carrete se hallan casi de forma testimonial con el $0,6 \%$ y el $0,2 \%$ respectivamente. Los objetos cerámicos, como fichas o pesas de telar, suponen el 1,3\%.

\section{Cazuelas}

Del 5,5\% de total, el 2,1\% corresponde a cazuelas de carena alta marcada y el $1,7 \%$ a cazuelas de carena alta suave. Los diámetros oscilan entre los 22 y los $31 \mathrm{~cm}$, mientras que los grosores de las paredes se sitúan entre los 4 y los $14 \mathrm{~mm}$.

Las cazuelas suelen tener pastas muy decantadas, de granulometría fina o media, y unas cocciones mayoritariamente reductoras, aunque existen algunas cocciones irregulares y puntuales cocciones oxidantes. Las superficies, generalmente bruñidas, presentan colores que oscilan entre el negro y el castaño oscuro (fig. 9, 2-3). Dicha coloración obedece a la cocción de la pieza, aunque en alguna se aplicó un engobe marrón rojizo (fig. 9, 1). El empleo del término "cazuela" responde a su uso generalizado en las tipologías de referencia, aunque las características técnicas de las piezas, unido a la ausencia de marcas por exposición al fuego, apuntan hacia su uso para el servicio o presentación de los alimentos.

En cuanto a la morfología, las cazuelas de carena alta marcada tienen siempre el borde exvasado, ya sea redondeado o apuntado. Su característica principal es la carena que se marca en el tercio superior del recipiente, desarrollándose desde este punto y hasta el borde un perfil más o menos cóncavo. En alguna ocasión, como ocurre en muchas de las cazuelas del tipo A.I.a de Ruiz Mata (1995: fig. 2), la carena reprodujo un escalón redondeado (fig. 3 , 1), mientras que en otros casos esta parte fue seleccionada para la aplicación de un mamelón con perforación vertical (fig. 3, 2), como ocurre en algunas cazuelas del estrato VIII de Setefilla (Aubet et al. 1983: fig. 35, 181) o del fondo XXXII-XXXIII de San Bartolomé (Fernández Jurado y Ruiz Mata 1986: lám. II, 6). La fragmentación de las cazuelas no ha permitido conocer los fondos, aunque sus paralelos apuntarían hacia fondos planos. 


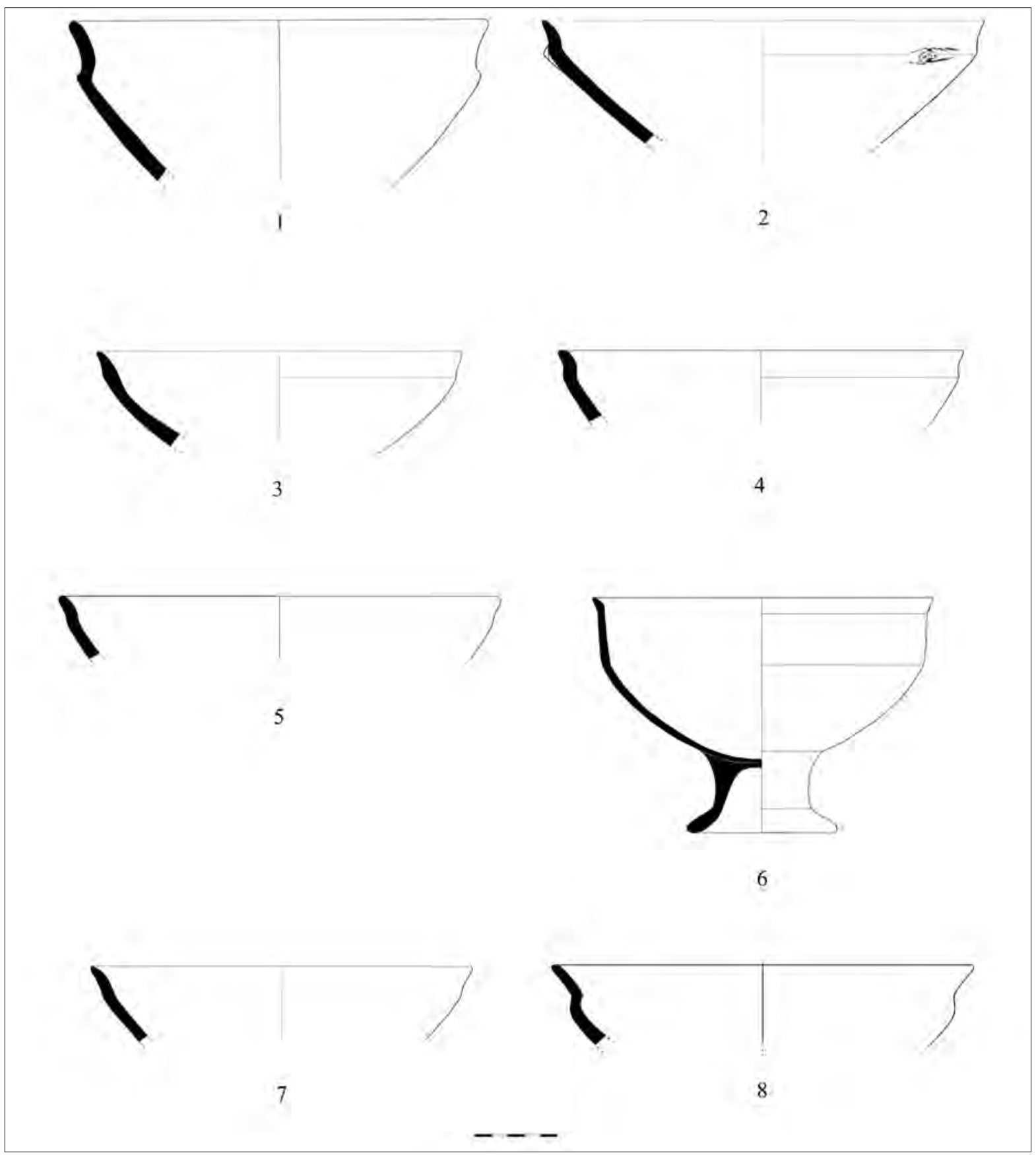

Fig. 3: Cazuelas.

Muchas de las cazuelas corresponden al tipo A.I.a de Ruiz Mata (1995: fig. 4, 8), concretamente a su variante Guadalquivir que se caracteriza por un borde almendrado y un rehundimiento interno a la altura de la carena (fig. 3, 2-3). Esta forma, asimilable al tipo A'16 de López Roa
(1977: 362) o 6C de González de Canales et al. (2010: fig. 14), halla su paralelo exacto en un ejemplar del fondo $\mathrm{V}$ de San Bartolomé (Fernández Jurado y Ruiz Mata 1986: fig. 32, 302), aunque también guarda grandes similitudes con algunas cazuelas A.I.a de la fase Ic del Cabezo de San Pedro 
(Ruiz Mata et al. 1981: figs. 38, 72, 90; 44, 225) y el estrato XI de Setefilla (Aubet et al. 1983: fig. 32, 140). Dicha forma perduró, aunque más escasamente, en la fase II del Cabezo de San Pedro (Ruiz Mata et al. 1981: figs. 49, 351; 50,$391 ; 56,542$ ) y en la fase III de Setefilla (Aubet et al. 1983: figs. 35, 181; 38, 225; 41, 245), considerándose residual en el nivel 2 de La Piterilla (Rufete 2002: lám. 2, 6). Otra variante con el borde más cóncavo (fig. 3,4 ) aparece en los niveles transicionales del Bronce Final-Hierro I del Cerro de las Cabezas (Esteban et al. 2003: fig. 6, 10-11), conviviendo con cazuelas de perfil más suave. La perduración de la cazuela A.I.a también se atestigua en el cercano yacimiento de La Bienvenida-Sisapo, estratificada en el nivel 13 del corte A1 (ab) (Fernández Ochoa et al. 1994: fig. 122) y en las fases 3 y 4 del edificio orientalizante del área 4 (Zarzalejos et al. 2017: 58, fig. 12, 7, 12). La primera de ellas y la documentada fuera de contexto en Casa de Rana (Pérez Avilés y Vélez 1996: lám. I, 5) se adscriben a la variante onubense de Ruiz Mata (1995), caracterizada por un borde más vertical y un pronunciado escalón en la carena.

Entre las cazuelas de carena alta destaca una de $22 \mathrm{~cm}$ de diámetro del borde, 9,2 cm de diámetro de base y 10,3 $\mathrm{cm}$ de profundidad (fig. 3, 6). Esta cazuela, sometida a análisis de contenido sin resultado positivo (García Huerta 2019: Anexo II: M4), presenta una carena media-alta y un pie indicado que le concedió un perfil de crátera muy característico. Fue hallada junto a un cuenco (fig. 4, 5) y un soporte de carrete (figs. 8, 1;9,9) en el nivel 3 de la U18-3 (U18-3-3), del que se extrajo una muestra de carbón (Beta473984) y otra de hueso (Beta-475572) para su análisis por C-14 (fig. 10). La forma recuerda a algunos vasos abiertos con pie indicado del SO (Aubet et al. 1983: fig. 59, 3; Ruiz Mata 1995: fig. 28, 1-3) y el centro de la Meseta (Blasco et al. 1991: fig. 30, 20), aunque el borde tiene su paralelo exacto en el cuenco incompleto del fondo XV-A de San Bartolomé (Fernández Jurado y Ruiz Mata 1986: lám. XXXVII, 519) y en un vaso del nivel 12 de Colina de los Quemados (Luzón y Ruiz Mata 1973: lám. XII, c).

En segundo lugar, se encuentran las cazuelas de carena alta suave (figs. 3, 5; 3, 7-8), asimilables al tipo A.II.a de Ruiz Mata (1995: 273), como las de la fase II del Cabezo de San Pedro (Ruiz Mata et al. 1981: figs. 52, 454455; 55, 516), la fase III de Setefilla (Aubet et al. 1983: fig. 34, 178), el fondo XIV-B de San Bartolomé (Fernández Jurado y Ruiz Mata 1986: láms. XLIII, 589-591; XLIV, 597), la fase V de El Carambolo (Fernández Flores y Rodríguez Azogue 2007: figs. 16, CAR-2528-7; 17, CAR-2576), Salsa 3 (Antunes et al. 2012: fig. 13, 3),
Monte do Bolor 3 (Antunes et al. 2017: fig. 5, 1. MBL.3. 10.1088) o el nivel 1 del Cerro de San Antonio (Blasco et al. 1991: fig. 29, 8, 18). En algunas se ha podido concretar su adscripción segura a la variante A.II.a.1 de Ruiz Mata (1995: fig. 4, 26) (fig. 3, 7), mientras que otras, con el borde redondeado y la carena algo más marcada (fig. 3 , 5), muestran más analogías con el tipo A.I-II.a (Ruiz Mata 1995: fig. 4, 36), como las del nivel 16 de Colina de los Quemados (Luzón y Ruiz Mata 1973: lám. VII, h), el fondo I.1 de San Bartolomé (Fernández Jurado y Ruiz Mata 1986: fig. 32, 1242) o la fase II del Cerro de la Cabeza (Ruiz Mata 1995: fig. 19, 3).

En dos de los casos, la carena mostró un destacado abombamiento que creó un cierto perfil en S (fig. 3, 8), acercándose al tipo III.A de Blasco et al. (1991: figs. 39, $14 ; 63,2)$ que aparece en el nivel 3 del Cerro de San Antonio y en el fondo XIV-A de San Bartolomé (Fernández Jurado y Ruiz Mata 1986: lám. XXV, 469).

\section{Fuentes}

Las escasas fuentes, con una proporción del 0,6\% del total de las formas registradas, presentan cocciones irregulares o reductoras y superficies que oscilan entre el castaño claro y el negro. El tratamiento de las superficies suele ser bruñido o alisado $y$, en ocasiones, fueron pintadas, como el excepcional ejemplar de perfil hemisférico adscrito al estilo Meseta (Miguel 2020: fig. VIII, 22). La calidad que reflejan estos tratamientos contrasta con otros ejemplares de pastas poco decantadas o desgrasantes medios o gruesos. Los perfiles son troncocónicos o hemisféricos, con diámetros entre 28 y $36 \mathrm{~cm}$ y paredes con un grosor entre 7 y $8 \mathrm{~mm}$.

Las grandes fuentes con mamelones triangulares en el borde (fig. 9, 4), datadas en algunos contextos del interior peninsular a partir del último cuarto del s. VII a.C. (Valenciano y Polo 2010: figs. 13-14), también se registraron en el nivel 3 del C-23 de Alarcos (Fernández Rodríguez 2012: fig. 10, 1-2), en este caso con una mayor antigüedad. En términos generales, se trata de una forma muy habitual en la Meseta durante el Hierro I, definiendo el tipo VI de Blasco et al. (1991: fig. 64).

\section{Cuencos}

Los cuencos, con el 43,3\% del total de individuos reconocidos, suponen los recipientes más abundantes. Los de carena alta suave, con un 11,3\% del total, son los más habituales, seguido por los cuencos sin carena $(9,5 \%)$ y los de carena alta marcada $(5,1 \%)$. 


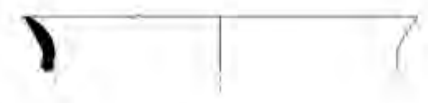

1

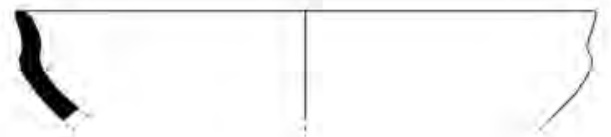

3

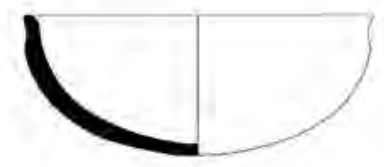

5

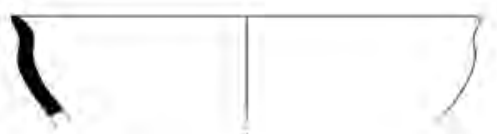

7

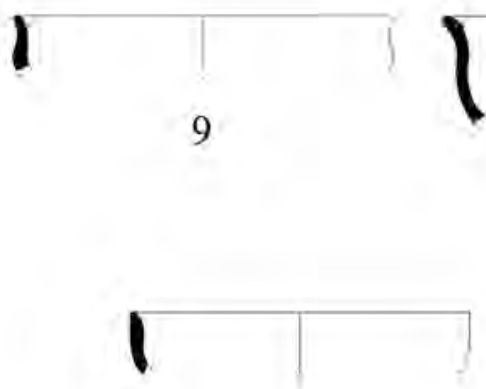

12

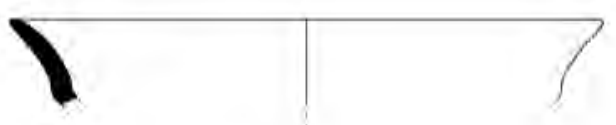

2

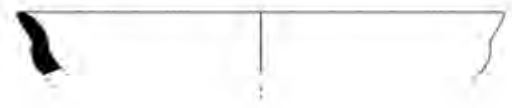

4

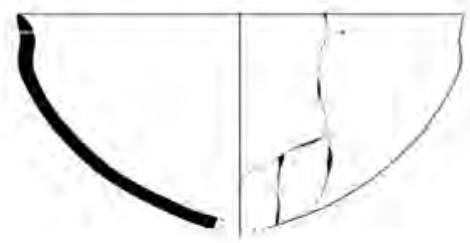

6

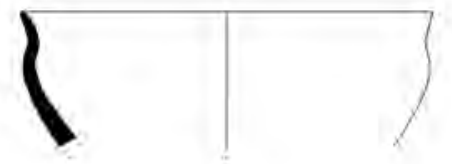

8

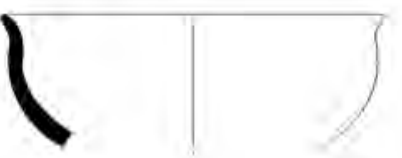

11

10

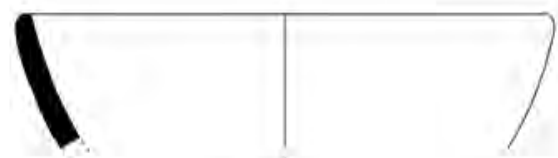

Fig. 4: Cuencos.

En cuanto a la técnica, destaca la maestría que los alfareros de Alarcos desarrollaron en estas formas que muchas veces no sobrepasaron el centímetro de grosor. Se trata de piezas excepcionales, con pastas muy decantadas y desgrasantes muy finos, casi imperceptibles. Las cocciones fueron mayoritariamente reductoras, aunque hay casos de 
nervios de cocción e incluso alguna de cocción oxidante. Las superficies, entre marrones y negras, destacan por un excelente bruñido que ofreció un aspecto muy brillante (fig. 9, 5-6). Todas estas características, unidas a la compacidad de las pastas, convierten a los cuencos en las piezas más sobresalientes del conjunto cerámico exhumado en Alarcos, de ahí que fuera el soporte más proclive para el desarrollo de la delicada decoración pintada (Miguel 2020).

En lo relativo a la morfología, los cuencos suelen reproducir las mismas formas que las cazuelas, aunque a menor escala. Sus diámetros se sitúan entre los 8 y los 20 $\mathrm{cm}$, aunque son más frecuentes aquellos entre los 10 y los $15 \mathrm{~cm}$, mientras que los grosores de las paredes suelen oscilar entre 1 y $9 \mathrm{~mm}$. Entre los cuencos de carena alta (fig. 4, 1-4), con el borde apuntado o redondeado, están aquellos con un característico perfil en Z (fig. 4, 1). Este tipo de cuencos se halla en Valencina de la Concepción con las mismas características (Ruiz Mata 1995: fig. 19, 1) o en cerro Macareno (Ruiz Mata 1995 fig. 19, 11), ambos adscritos al Hierro I al igual que los ejemplares análogos de la Meseta (Blasco et al. 1991: fig. 44, 20). De Cerro Macareno (Ruiz Mata 1995: fig. 19, 20) también procede la versión con el borde más desarrollado y sin el anterior tramo recto (fig. 4,2), aunque es más próximo el ejemplar del Bronce Final-Hierro I del Cerro de las Cabezas (Esteban et al. 2003: fig. 6, 7).

En otras ocasiones, los cuencos de carena alta pronunciada reprodujeron el perfil de las copas B.I de Ruiz Mata (1995: fig. 7) (fig. 4, 3), concretamente la variante de carena marcada redondeada y borde más vertical que aparece en el fondo XIV-A de San Bartolomé (Fernández Jurado y Ruiz Mata 1986: fig. 34). Los cuencos del tipo B.II.a también aparecen representados, siendo muy habituales en la fase II del Cabezo de San Pedro (Ruiz Mata et al. 1981: figs. 53, 459; 56, 542, 572; 61, 684; 63, 728, 735).

Los cuencos de carena alta suave corresponden a la forma B.II.b.1 de Ruiz Mata (1995). Son muchos los elementos morfológicos que se podrían distinguir con respecto a la dirección del borde, algo típico de las cerámicas a mano en las que existen múltiples variables formales, aunque todos tienen en común la configuración de un perfil carenado suave que los integran sin problemas en este tipo. El cuenco B.II.b.1 aparece en Monte do Bolor 3 en los ss. VII-VI a.C., (Antunes et al. 2017: 166, fig. 5, 1. MBL3.10.1200). También aparecen en la Cuesta de los Cipreses (Ferrer et al. 2017: fig. 8, 14) y, de forma abundante y pintados al estilo Meseta, en la tumba de El Carpio (Pereira 2019: figs. 3-5) fechada a principios del s. VII a.C.
En los porcentajes de los cuencos de carena alta suave se han incluido aquellos que podrían considerarse formas transicionales entre los cuencos de carena alta suave y los cuencos sin carena (fig. 4, 5-9), ya que existe una ligera protuberancia en el tercio superior que corresponde al punto en el que se desarrolló la carena en los cuencos carenados. Se trata de la forma B.II.c de Ruiz Mata (1995) en la que se pueden distinguir algunas variantes en función de la agudeza del estrangulamiento del cuello y la verticalidad del borde. Los bordes pueden ser apuntados o redondeados, con una base umbilicada en el único ejemplar completo. Este tipo de cuencos se fecharon en Rocha do Vigio 2, junto a un cuenco del tipo B.II.b.1, entre finales del s. IX y principios del VIII a.C. (Mataloto 2012: 202-203, fig. 21, 1-2), aunque en el cercano yacimiento del Cerro de las Cabezas se halla en un contexto algo más reciente (Esteban et al. 2003: fig. 6, 6).

Por último, se encuentran los cuencos sin carena (fig. 4, 10-13), casi todos asimilables al tipo B4a de González Prats (1983) o B.II.d de Ruiz Mata (1995: 276) (fig. 4, 10-11). Dichos cuencos, con un característico perfil en $S$, responden a una forma simple de perfil hemisférico y borde exvasado que puede ser apuntado o redondeado. En cuanto a la profundidad, existen ejemplares con una mayor verticalidad y profundidad, concretamente con una altura máxima conservada de 3,4 cm. Esta forma aparece en los fondos II (Fernández Jurado y Ruiz Mata 1986: fig. 34; Ruiz Mata 1995: fig. 4, 43-44) y XI de San Bartolomé (Fernández Jurado y Ruiz Mata 1986: fig. 34). Algunos presentan un borde vuelto, como el paralelo de Torre Velha 3 fechado entre los ss. VII-VI a.C. (Antunes et al. 2017: 180, fig. 14, tercera fila-dcha).

Entre los cuencos sin carena también se encuentran aquellos con bordes rectos y sin el perfil en $\mathrm{S}$ que caracterizaba a los anteriores (fig. 4, 12). Por último, está el cuenco de algo menos de media esfera, relacionado con el tipo 2E de González de Canales et al. (2010: fig. 14) y representado únicamente por un ejemplar con una altura máxima conservada de 4,5 cm (fig. 4,13). Tiene un cierto perfil cónico y un borde recto ligeramente entrante que guarda grandes paralelismos con el recipiente de pie indicado del nivel 11 de Colina de los Quemados (Luzón y Ruiz Mata 1973: lám. XIX, b) y algunos vasos del fondo VII de San Bartolomé (Fernández Jurado y Ruiz Mata 1986: lám. LXVII, 927) y la fase II de Castro Marim (Arruda et al. 2017: fig. 4, 11-12), aunque habría que admitir que se trata de una forma simple muy común en varios periodos y culturas. Así, en el cercano yacimiento 
Fig. 5: Platos.

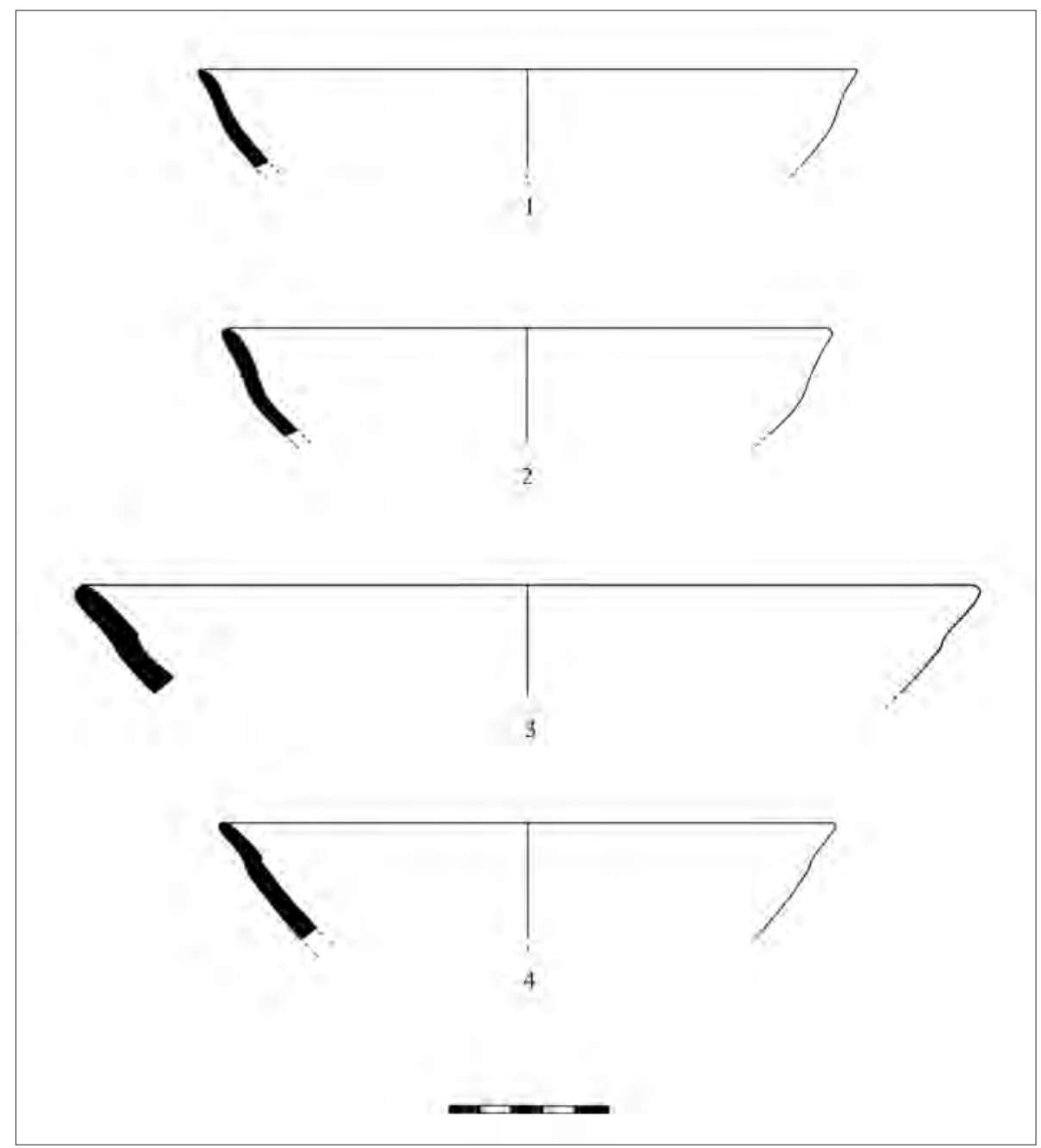

de Calatrava la Vieja se ubica en la UE 80, adscrita a un momento avanzado del Hierro I o de transición al Ibérico Antiguo (Miguel 2019: fig. 3, 1), mientras que en el Cerro de las Cabezas se encuadra en un contexto transicional del Bronce Final al Hierro I (Esteban et al. 2003: fig. 6,9).

\section{Platos}

Los platos representan el 2,6\% del total de formas registradas, con diámetros entre los 15 y los $27 \mathrm{~cm}$, aunque la mayoría oscila entre los 19 y los $27 \mathrm{~cm}$. Los grosores de las paredes están entre los 5 y los $8 \mathrm{~mm}$.

Los platos se caracterizan por unas pastas menos decantadas que en el caso de los cuencos, siendo habitual los desgrasantes de granulometría media. Esta menor calidad también se detecta en el tratamiento de las superficies, muchas alisadas por ambos lados. Sin embargo, también existen platos con pastas muy depuradas y superficies bruñidas. Las cocciones suelen ser reductoras o irregulares, concediendo a las superficies unos colores castaños, marrones oscuros o negros (fig. 9, 7).

En lo que respecta a la morfología, la mayoría de los platos, con el borde exvasado y redondeado, muestran un sencillo perfil en $\mathrm{S}$ o reproducen el perfil de las cazuelas A.II.a. (fig. 5, 1). Algún ejemplar muestra un pequeño escalón interno para diferenciar el borde del cuerpo (fig. 5, 3-4). Esta característica, que define al tipo 11C1 de González de Canales et al. (2010: fig. 15), aparece en algunos platos de la fase III de Setefilla (Aubet et al. 1983: figs. 38, 210; 41, 248) y en un plato de casquete esférico de la fase I-II de San Bartolomé (Fernández Jurado y Ruiz Mata 1986: fig. 32, 743). 


\section{Recipientes esferoides y elipsoides}

Los recipientes cerrados suponen el $26,3 \%$ del total registrado, aunque solo se han podido reconstruir dos formas, recipientes de cuerpo esférico (fig. 6, 1-4), con una proporción del 1,5\%,y los de cuerpo elipsoide (figs. $6,5-8 ; 7,1)$, con el 3,6\% del total de formas. La mayor parte de los fragmentos que presuponen estas formas cerradas, reconocidas por la similitud en los tratamientos de las superficies, corresponden a bordes o bases planas que no han permitido concretar su adscripción segura a estos dos grupos diferenciados (fig. 7, 5-7).

La mayoría de estos recipientes presentan superficies toscas o un ligero alisado, aunque hubo algunos que tuvieron un tratamiento diferente, como un vaso à chardon cuyas superficies fueron bruñidas (fig. 9, 11). Las incisiones, sobre todo a lo largo del borde (fig. 7, 2-3), también fue una característica en este tipo de recipientes, aunque también se desarrollaron en sucesión a lo largo del hombro (fig. 8, 8) o del cuerpo (fig. 9, 11).

Las cocciones suelen ser irregulares o reductoras, ofreciendo unos tonos entre castaño y negro para ambas superficies y las pastas. Muchas de estas piezas tienen manchas negras relacionadas con una prolongada y asidua exposición al fuego. Esta característica, junto con el descuido de las superficies, relaciona algunos de estos recipientes con la cocina o procesado de alimentos, aunque muchos de ellos también pudieron emplearse como recipientes de almacenamiento.

Dentro de estos dos tipos, establecidos en función del perfil del cuerpo, se han podido distinguir variantes que se han determinado según algunos elementos morfológicos. De esta forma, dentro de los recipientes de cuerpo esférico, destacan aquellos que, con un borde plano, redondeado o apuntado, pueden mostrar una dirección recta, exvasada o invasada.

Los más numerosos son los de borde invasado o entrante (fig. 6, 1-3), relacionados con la forma A3 de González Prats (1983) o 13E de González de Canales et al. (2010: fig. 15), con diámetros entre los 22 y los $29 \mathrm{~cm}$ y paredes entre los 11 y $12 \mathrm{~mm}$ de grosor. Uno de ellos se decoró con un mamelón a la altura del borde e incisiones a lo largo del labio (fig. 6, 1). Se trata de una forma simple, muy común en varias culturas y periodos. En contextos del Bronce Final y la Primera Edad del Hierro aparece en los fondos X-B (Fernández Jurado y Ruiz Mata 1986: lám. I, 18-20), XXXII-XXXIII (Fernández Jurado y Ruiz Mata 1986: lám. IX, 147), I-2 (Fernández Jurado y Ruiz Mata 1986: lám. LVII, 773) y VIII de San Bartolomé
(Fernández Jurado y Ruiz Mata 1986: lám. XC, 1127), calle Méndez Núñez 7-13/Plaza de las Monjas 12 (González de Canales et al. 2010: fig. 15), el fondo A del Jardín de Alá (Hunt y García Rivero 2017: fig. 29, JA-62), Cuesta de los Cipreses (Ferrer et al. 2017: figs. 7, 9, 11; 22, 203-5; 23, 404-11), la Escuela de Hostelería de Mérida (Jiménez y Heras 2017: fig. 6, tercera fila izquierda) o Salsa 3 (Antunes et al. 2017: fig. 11, 24), este último con decoración digitada. El paralelo más cercano se encuentra, también con un mamelón vertical por debajo del borde, en la fase III de Castro Marim (Arruda et al. 2017: fig. 6,13 ). En la meseta también son frecuentes en estas fases culturales, como se muestra en el Cerro de San Antonio (Blasco et al. 1991: fig. 35, 17, 21).

Los recipientes de cuerpo elipsoide u ovoide (fig. 6 , 5-8), entre los 12 y los $28 \mathrm{~cm}$ de diámetro y los 5 y 14 $\mathrm{mm}$ de grosor, suelen tener el borde redondeado o ligeramente apuntado. También se aprecia en ellos una diferenciación a partir del estrangulamiento del cuello que puede ser más o menos acusado.

Todos estos recipientes de cuerpo elipsoide pertenecen al tipo G.I de Ruiz Mata (1995: fig. 14), el cual define a un conjunto de ollas con el borde diferenciado del cuerpo en el que se han establecido algunos subtipos. Así, hay ollas que se ajustan al subtipo G.I.a.1, concretamente aquella variante caracterizada por un hombro muy marcado del que parte un cuello entrante que finaliza en borde recto o ligeramente exvasado (fig. 6, 5) (Ruiz Mata 1995: fig. 14: 1), como las de la fase I (Ruiz Mata et al. 1981: figs. 35, 5; 36, 21), II (Ruiz Mata et al. 1981: fig. 60,653 ) y III del Cabezo de San Pedro (Ruiz Mata et al. 1981: fig. 80,4). También aparecen en los fondos XXXIIXXXIII (Fernández Jurado y Ruiz Mata 1986: láms. X, 166; XI, 167, 169, 171-174), V (Fernández Jurado y Ruiz Mata 1986: lám. XXII, 332; XXIV, 339) y II de San Bartolomé (Fernández Jurado y Ruiz Mata 1986: lám. LXXXI, 1041) o el fondo F del Jardín de Alá (Hunt y García Rivero 2017: fig. 31, JA-262).

Otra variante con el hombro marcado, correspondiente a la forma 12C de González de Canales et al. (2010: fig. 15), muestra un borde más exvasado que agudizó el estrangulamiento del cuello (fig. 6, 6) (Ruiz Mata 1995: fig. 14, 2). Esta forma también se atestigua en la fase I (Ruiz Mata et al. 1981: fig. 37,33) y II del Cabezo de San Pedro (Ruiz Mata et al. 1981: fig. 54, 502; 59, 622), las fases III y IV de Setefilla (Aubet et al. 1983: figs. 32, 157; 43, 297), los fondos XXXII-XXXIII (Fernández Jurado y Ruiz Mata 1986: lám. XI, 168) y V de San Bartolomé 


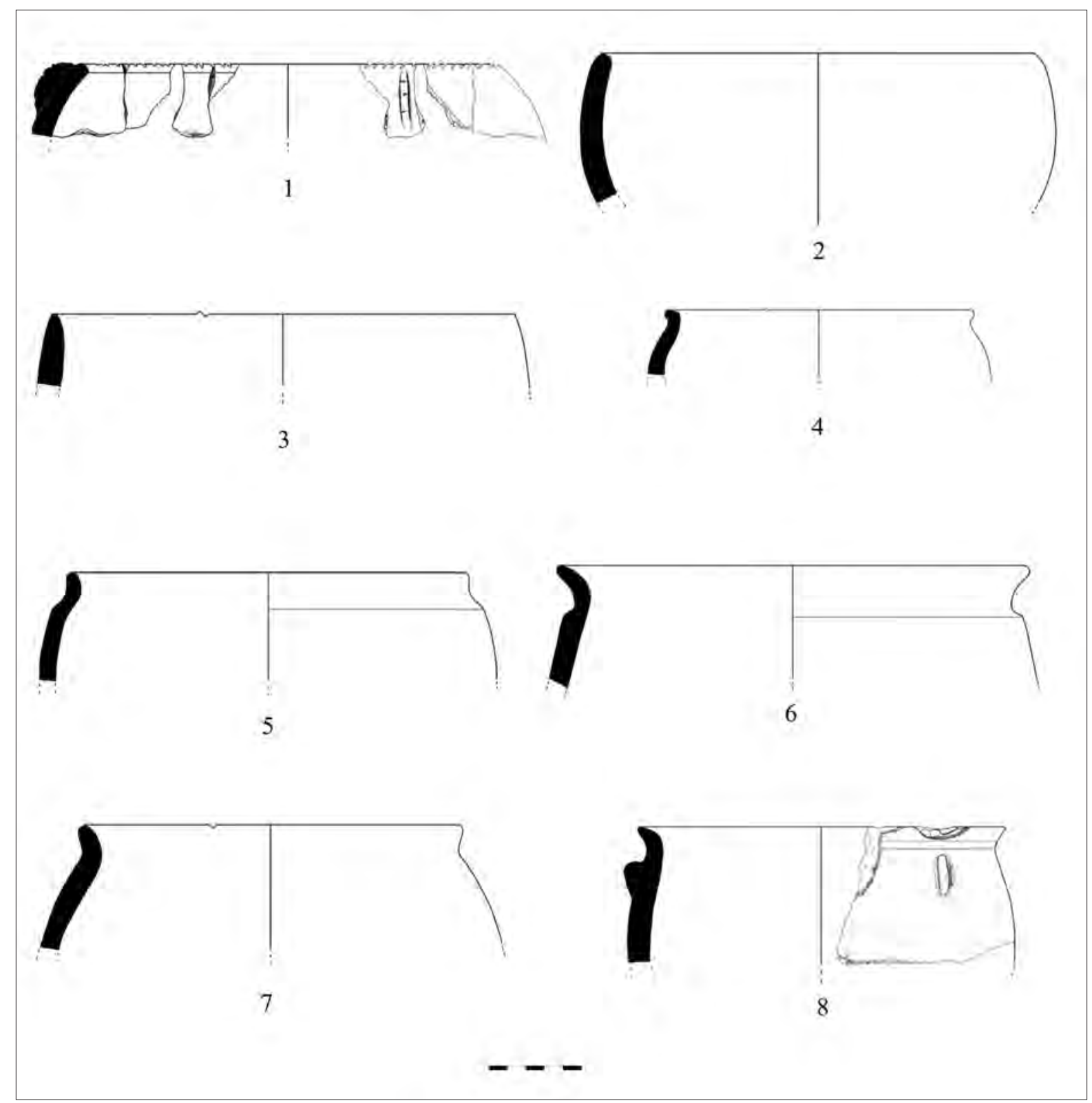

Fig. 6: 1-4. Recipientes esferoides; 5-8. Recipientes elipsoides.

(Fernández Jurado y Ruiz Mata 1986: lám. XXIII, 334), la U.E. 15c de El Carambolo (Fernández Flores y Rodríguez Azogue 2007: fig. 53, CAR-15C-14), Torre Velha 3 (Antunes et al. 2017: fig. 14, 1 abajo-izquierda) y los fondos F (Hunt y García Rivero 2017: fig. 31, JA334) y J del Jardín de Alá (Hunt y García Rivero 2017: fig. 33, JA-820), a veces con el típico mamelón en el hombro del recipiente (Ruiz Mata et al. 1981: figs. 36,
20; 37, 32; 38, 62; 41, 160; Fernández Jurado y Ruiz Mata 1986: láms. XI, 180; XXIII, 333; XXVI). En el Alto Guadiana aparece esta forma sin contexto y con decoración grafitada en Calatrava la Vieja (Miguel 2019: fig. 5, 3), aunque en La Bienvenida-Sisapo se estratifica, con decoración digitada, en los niveles del Hierro I (Fernández Ochoa et al. 1994: figs. 116, 42-43; $118,51 ; 119,57)$. 


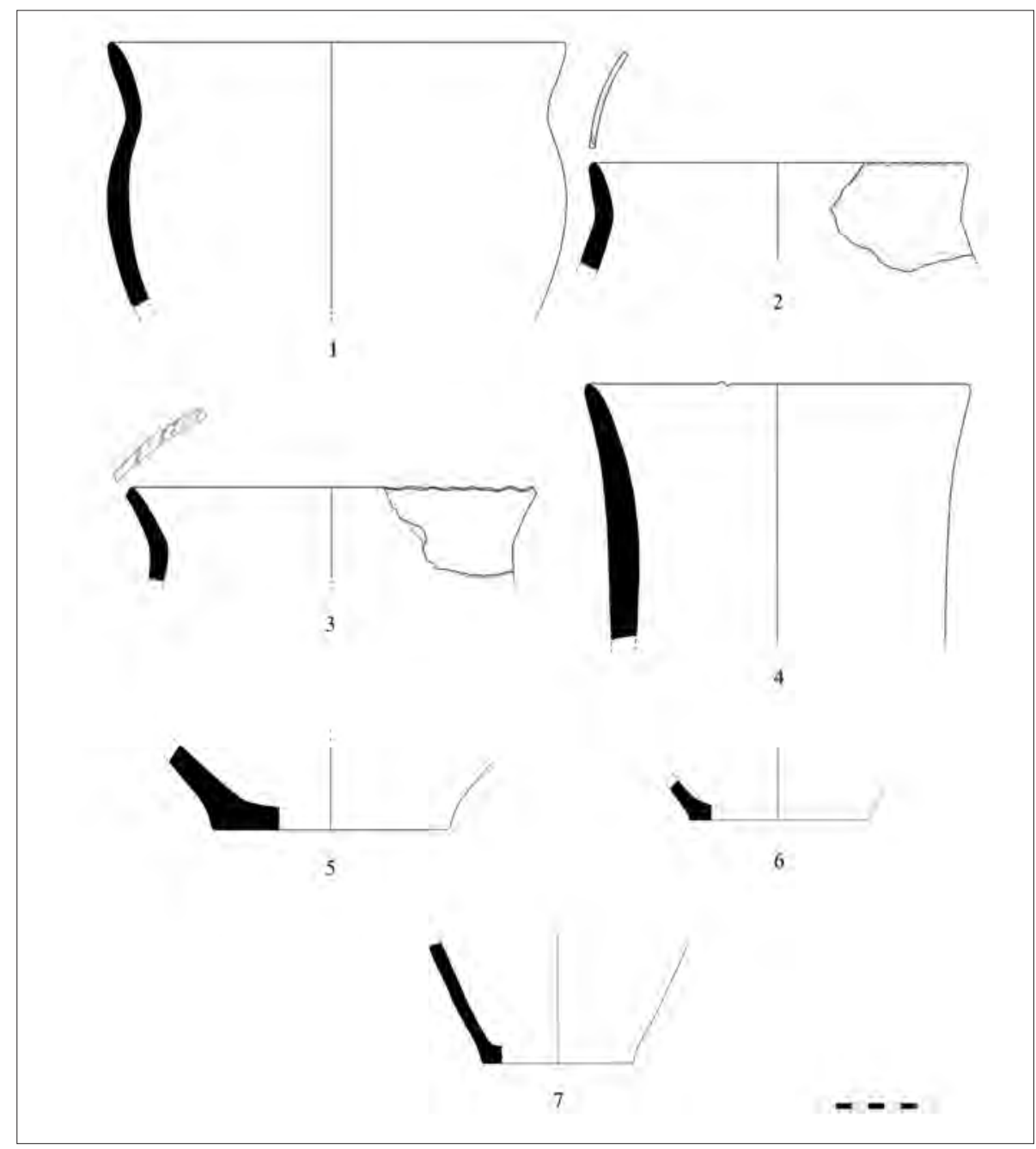

Fig. 7: 1. Recipiente elipsoide; 2-3. Bordes con incisiones; 4. Perfil acampanado; 5-7. Bases planas.

En ocasiones, el hombro no quedó marcado (fig. 6, 7-8), aunque el cuello se estranguló por el exvasado de un borde muy corto, dando lugar a un perfil en $\mathrm{S}$ más suave y continuo que ocasionalmente aplicó un mamelón por debajo del borde (figs. 6, 8; 9, 8). Estas características, que definen al tipo G.I.a.2 de Ruiz Mata (1995: fig. 14, 4), aparecen en la fase I del Cabezo de San Pedro (Ruiz Mata et al. 1981: figs. 36, 14) y en los fondos XXXII-XXXIII (Fernández Jurado y Ruiz Mata 1986: lám. XIII, 199-200, 203) y V de San Bartolomé de Almonte (Fernández Jurado y Ruiz Mata 1986: lám. XXIV, 341-342), aunque también se registra en el Cerro de las Cabezas (Esteban et al. 2003: fig. 4, 4), la fase 3 del edificio orientalizante del área 4 de La Bienvenida-Sisapo (Zarzalejos et al. 2017: fig. 12,4), Salsa 3 (Antunes et al. 2017: fig. 11, 26), Cabeço Redondo (Monge Soares y
Monge Soares 2017: fig. 12, 2), el Cerro de San Antonio (Blasco et al. 1991: fig. 44, 19) y en la Escuela de Hostelería (Jiménez y Heras 2017: figs. 6, primera fila derecha, segunda fila izquierda, cuarta fila izquierda; 7 , segunda fila izquierda). Todos estos testimonios muestran una gran amplitud cronológica que prácticamente ocupa todo el Hierro I. Uno de los paralelos más claros, fechado en la segunda mitad del s. VII a.C., se encuentra en la fase III de Castro Marim (Arruda et al. 2017: fig. 6, 1-2), contexto en el que, al igual que Alarcos, el recipiente se asocia a cerámica estilo Medellín.

Cuando el tramo del cuello fue más amplio adquirió la forma de las ollas del tipo G.I.c (Ruiz Mata 1995: fig. 14, 9) o I.B de Blasco et al. (1991: fig. 62, 6), como el ejemplar que se halló prácticamente completo en el nivel 3 de la U18-2, junto al testigo N (fig. 7, 1). Esta forma, 
que ocasionalmente muestra incisiones a lo largo del borde (fig. 7, 2-3), también aparece en otros yacimientos de la Primera Edad del Hierro de la meseta con esta misma decoración, como en el Cerro de San Antonio (Blasco et al. 1991: figs. 20, 8; 37, 1, 4-5), si bien parece ser un recurso decorativo habitual en el Alto Guadiana como demuestran los vasos análogos del Cerro de las Cabezas (Esteban et al. 2003: fig. 4, 7).

Entre los recipientes de cuerpo ovoide se encuentran aquellos con el cuello muy desarrollado y con un perfil acampanado (figs. 7, 4; 9, 11), clasificado como urna por Fernández Jurado y Ruiz Mata (1986: fig. 36), aunque en los estudios cerámicos de la Primera Edad del Hierro son más conocidos como vaso à chardon. Este vaso, cuya mitad fue hallada en las anteriores campañas (García Huerta y Morales 2017: fig. 6), se elaboró a mano desde finales del s. IX a.C. (Torres 2008a: 659; Mataloto 2012: 202 203, fig. 21, 10), aunque la cronología radiocarbónica de Setefilla elevaría el límite superior entre el 840 y el 820 cal. a.C. (Brandherm y Krueger 2017: fig. 6). Precisamente el vaso à chardon o E.II.b del túmulo $\mathrm{B}$ de Setefilla es el que guarda mayores similitudes con el de Alarcos (Ruiz Mata 1995: fig. 23, 3), aunque también habría que considerar las formas análogas de la sepultura 4 de Poço Novo I (Figueiredo y Mataloto 2017: fig. 8, 4) y la urna acampanada del conjunto 70/12A-3 de la necrópolis de Medellín (Almagro y Torres 2008: 736), ambos fechados entre mediados y finales del s. VII a.C. Es muy probable que algunos de los bordes acampanados registrados, en especial uno de $52 \mathrm{~cm}$ de diámetro y superficies bruñidas (fig. 7, 4), pertenezcan a esta forma, aunque su fragmentación impide su clasificación segura.

El vaso à chardon es una forma típica de los contextos funerarios tartésicos onubenses (Garrido y Orta 1978: figs. 16, 30-31; 103, 1) y del Bajo Guadalquivir (Ruíz Mata 1995: figs: 22-24), aunque también se extendieron por el S de Portugal (Arruda et al. 2017: fig. 10, 1; Santos et al. 2017: fig. 14, abajo izquierda; Figueiredo y Mataloto 2017: fig. 10, 4) y el Guadiana Medio (Almagro 1977: figs. 100; 101: abajo derecha; Torres 2008a: 658-622). Durante el s. VIII a.C. se utilizó como urna cineraria, aunque a finales del mismo empezó a usarse como vaso de ofrendas (Torres 2008a: 659), perdurando a mano hasta el s. VI a.C. (Arruda et al. 2017: fig. 10, 1). En el nivel 13 de La Bienvenida-Sisapo también se conserva un ejemplar de este tipo a mano (Fernández Ochoa et al. 1994: fig. 125, 22), posiblemente con un uso funerario según la interpretación de dicho nivel (Zarzalejos et al. 2012: 28).
Sin embargo, el hecho de que sean los contextos funerarios donde se documenten los ejemplares más completos no quiere decir que estén ausentes en los poblados. Así, el vaso à chardon se ha constatado en el cerro Macareno (Pellicer et al. 1983: fig. 70, 553) o en el poblado de Alarcos como los ejemplares presentados. No obstante, cuando aparecen en poblados es mayoritaria su presencia en contextos cultuales, como santuarios (Torres 2008a: 659; Santos et al. 2017: 254).

\section{Soportes de carrete}

Los soportes de carrete quedan reducidos a un único ejemplar completo de $14 \mathrm{~cm}$ de diámetro, $9 \mathrm{~cm}$ de altura y $12 \mathrm{~mm}$ de grosor máximo (figs. 8, 1; 9, 9). Presenta una pasta depurada de granulometría fina, nervio de cocción y unas superficies muy bruñidas que oscilan entre el castaño y el negro. Quizás muchos de los pequeños bordes que se presuponen acampanados pertenezcan a esta forma, aunque su fragmentación no permite afirmarlo con seguridad.

Esta forma, que solo supone el 0,2\% del total, se corresponde con el tipo D.II de Ruiz Mata (1995: fig. 21). Es muy típica en el $\mathrm{S}$ peninsular, como en las tumbas 1 (Orta y Garrido 1963: fig. 15, 2) y 12 de la necrópolis de la Joya (Garrido y Orta 1978: fig. 17, 3), el nivel 24 del corte V-20 de cerro Macareno (Pellicer et al. 1983: fig. 68, 417), el nivel VI del cerro de los Infantes (Molina et al. 1983, 694), en la fase V de El Carambolo (Casado 2015: fig. 51, DJ/2002/24/2544-93+94+97) o la tumba E5 del CE1 de la necrópolis del cerro del Viento (Lechuga y Soto $2017,16 \mathrm{n}^{\circ}$ 6), todos del Hierro I.

\section{Otros elementos cerámicos}

En este apartado se encuentran todos aquellos elementos realizados en cerámica que no corresponden a recipientes y que suponen el 1,3\% del total del material cerámico recuperado. Dichos elementos se reducen a tres fichas (fig. 8, 2), una posible impronta de cestería (fig. 8, 3) y dos elementos circulares con una perforación central (fig. 8, 4-5), quizás pesas de telar como han apuntado García Huerta et al. (2020: 48).

Las fichas (fig. 8, 2), entre los 7 y $11 \mathrm{~mm}$ de grosor y entre los 4 y $10 \mathrm{~cm}$ de diámetro, presentan una pasta semidecantada o muy depurada, con desgrasantes finos o medios y cocciones irregulares o reductoras. Las superficies, entre castañas y negras, suelen tener las superficies alisadas, bruñidas o alternando ambos tratamientos.

Las pesas de telar (fig. 8, 4-5), con pasta de granulometría gruesa o media y cocción reductora, presentan 


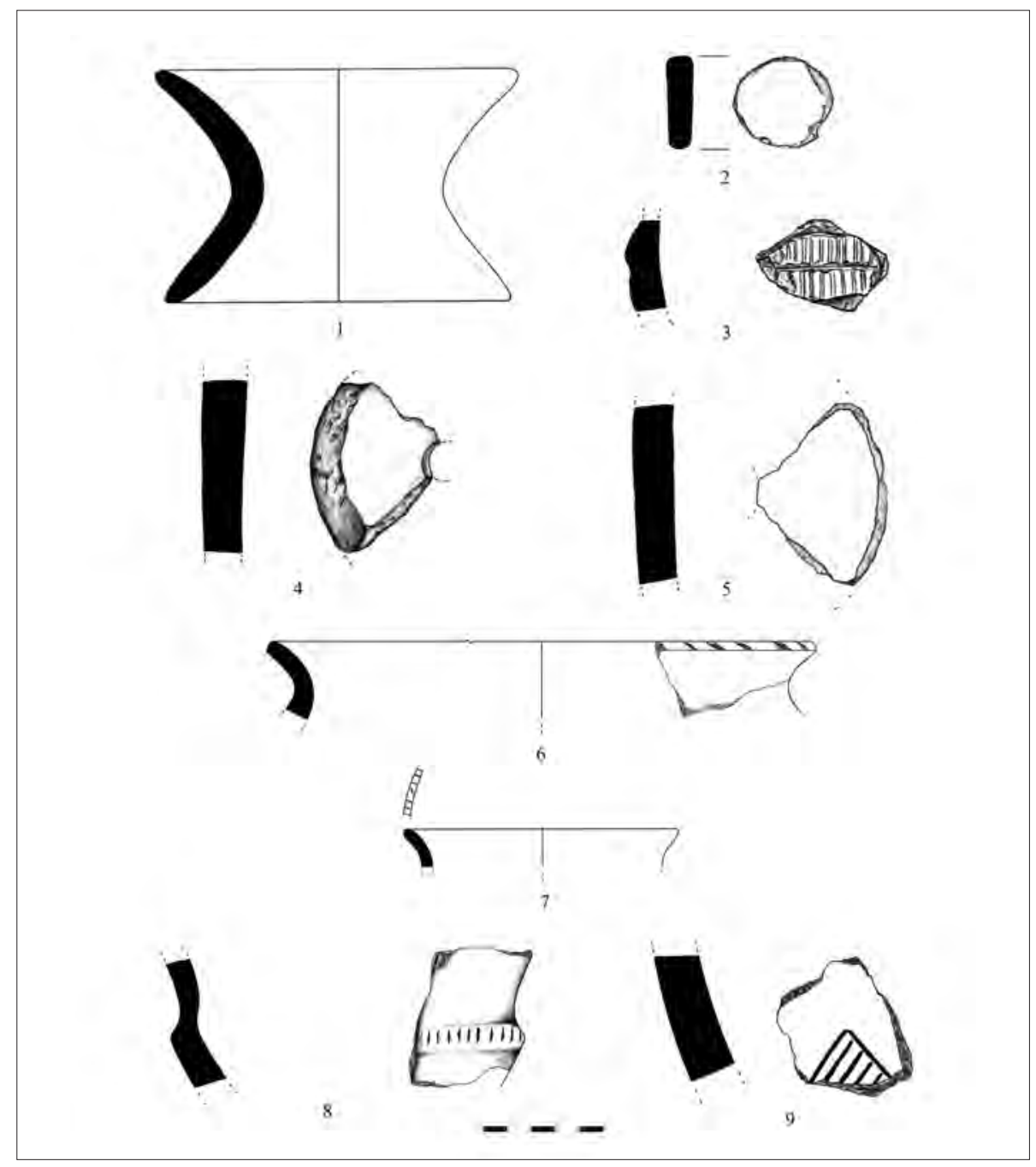

Fig. 8: 1. Soporte de carrete; 2. Ficha de cerámica; 3 . Posible impronta sobre cerámica; 4-5. Pesas de telar; 6-9. Bordes y galbos con decoración incisa.

unos grosores entre 13 y $17 \mathrm{~mm}$ y un diámetro entre los 10 y $12 \mathrm{~cm}$. Las superficies, entre beige y marrón, suelen estar alisadas o arrasadas. Tanto las fichas como las pesas de telar se elaboraron frecuentemente a partir de la reutilización de galbos.

\section{LAS DECORACIONES}

En lo relativo a la decoración, se observa el predominio de las cerámicas sin decorar, con el 74,5\% del total de cerámica documentada. Por su parte, la cerámica pintada supone el 19,3\%, correspondiendo el $13,23 \%$ al estilo San Pedro II, el 3,8\% al estilo Meseta, el 1,7\% a la cerámica monocroma en amarillo, el 0,6\% al estilo Medellín y el 0,4\% al estilo Valcorchero (Miguel 2020).

En cuanto a la concentración de la cerámica a mano con decoración pintada, cuyo estudio exhaustivo ha sido recientemente publicado (Miguel 2020), la cerámica estilo San Pedro II y estilo Meseta aparecen asociadas en todos los niveles constatados, destacando su importante proporción en los niveles 3 y 4 de la U18-2. En ambos niveles también es donde se han hallado los nueve únicos fragmentos de cerámica monocroma en amarillo, localizándose un fragmento de cerámica estilo Medellín en el nivel 1 de la U18-1 y dos en el nivel 3 de la U18-3.

La cerámica incisa (figs. 6, 1; 7, 2-3; 8, 6-9), con el $3,6 \%$ de la cerámica decorada, muestra un repertorio exclusivamente geométrico, como triángulos (fig. 8, 9), líneas horizontales, círculos, etc. que fueron ejecutados con un instrumento romo cuando el barro estaba fresco Fue muy habitual la decoración de incisiones sucesivas a lo largo de los bordes de los recipientes esferoides y elipsoides (figs. 6, 1; 7, 2-3; 8, 6-7), documentándose algún 


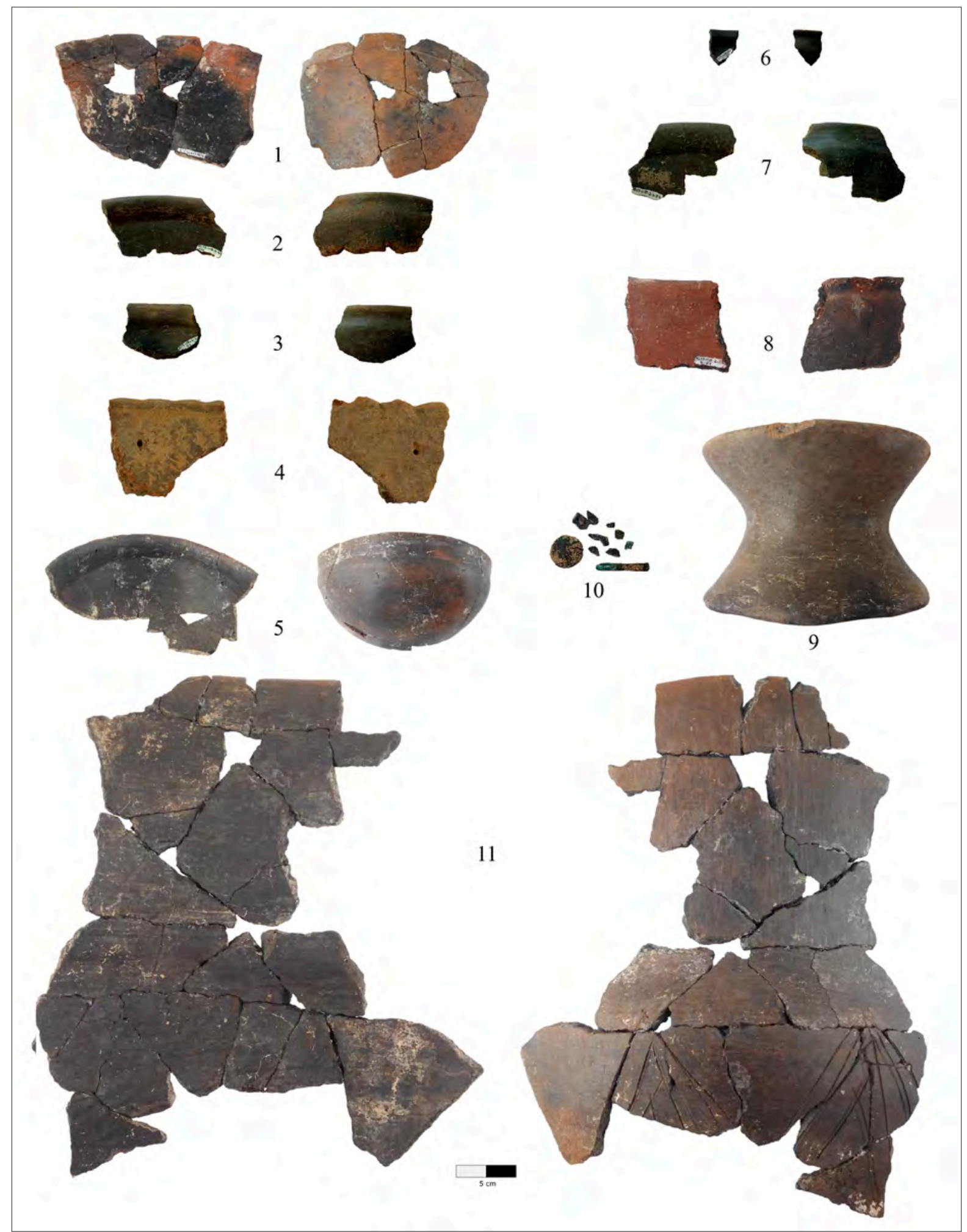

Fig. 9: Selección de materiales exhumados en 2017: 1-3. Cazuelas; 4. Fuente; 5-6. Cuencos; 7. Plato; 8. Olla con mamelón; 9. Soporte de carrete; 10. Restos de pieza de bronce; 11 . Vaso à chardon con decoración incisa. 
caso con incisiones a lo largo del hombro (fig. 8, 8). La cerámica incisa se documenta en todos los niveles constatados, destacando la decoración en el vaso à chardon del nivel 2 de la U18-2 (fig. 9, 11), una composición con una ejecución ligera y poco cuidada, como si fuera fruto de una reacción espontánea.

La tendencia por decorar los bordes a partir de incisiones continuas fue muy habitual en yacimientos del Hierro I de la meseta, como el cerro de San Antonio (Blasco et al. 1991: figs. 19, 2; 20, 1; 25, 18-20; 26, 5-7; 29, 1-7).

Las aplicaciones mamilares (figs. 6, 1 y 8; 9, 4 y 8), que supone el $1,5 \%$ del total de la cerámica decorada, suele restringirse a recipientes esferoides y elipsoides de superficies toscas, localizándose fundamentalmente por debajo de los bordes. Sin embargo, los mamelones también se aplicaron sobre los bordes de fuentes troncocónicas (fig. 9,4) o semiesféricas y en las carenas de algunas cazuelas (fig. 3, 2). Los mamelones aparecen frecuentemente perforados para su probable suspensión, ya sea horizontal o vertical. Los recipientes con mamelones aparecen en los niveles U18-3-1, U18-3-2, U18-3-3-1 y, especialmente representados, en el nivel 4 de la U18-2.

\section{METALES}

Entre el repertorio material se pudieron recuperar algunos elementos amorfos de bronce cuya mala conservación no han permitido su identificación. Dichos restos aparecen en el nivel 2 de la U18-3 y en el nivel 1 de la U18-2, en este caso un botón circular y un vástago de sección plana (fig. 9, 10).

\section{INDUSTRIA ÓSEA}

En el nivel 3 de la U18-3 también apareció un elemento alargado con algunas marcas de trabajo, aunque no se ha podido concretar su forma ya que aparece muy fragmentado.

\section{INDUSTRIA LÍTICA}

Los elementos líticos se reducen a tres cantos de río, probablemente utilizados como bruñidores o piedras de afilar, y restos amorfos de roca volcánica que pudieron formar parte de algún molino de mano como fue habitual en la zona y en el propio yacimiento en época íbera (García Huerta et al. 2020: 119). Sin embargo, ninguno de estos elementos líticos presenta marcas o evidencias de transformación por el ser humano, por lo que podría tratarse de materia prima sin un uso establecido.

\section{ALARCOS Y EL ALTO GUADIANA EN LA TRAN- SICIÓN BRONCE FINAL-HIERRO I Y HIERRO I}

Durante la etapa transicional Bronce Final-Hierro I y, sobre todo, durante el Hierro I se observa en el Alto Guadiana una tendencia hacia los elementos arqueológicos que definen a la cultura tartésica, ya sea en la arquitectura (Zarzalejos et al. 2017) o en las formas y decoraciones cerámicas (Esteban et al. 2019; García Huerta 2019; García Huerta et al., 2020; Miguel 2020). Tanto es así que hay autores que han reivindicado la plena inclusión de esta región en las dinámicas culturales de Tarteso (Zarzalejos et al. 2017: 42-43). Sin embargo, como se apuntó anteriormente, los datos estratificados aún son escasos para establecer una seriación contrastada de los materiales que definen estas etapas en el Alto Guadiana, si bien es cierto que en los últimos años se han logrado grandes avances gracias a las intervenciones sistemáticas y continuadas en yacimientos como Alarcos, La BienvenidaSisapo, el cerro de las Cabezas o Calatrava la Vieja.

En el estudio de las cerámicas de Alarcos se ha podido comprobar la existencia de materiales que remiten en su mayoría al Hierro I del SO peninsular, como el vaso à chardon con decoración incisa, la cerámica a mano pintada estilo Medellín o estilo San Pedro II, así como las cazuelas A.II, cuencos B.II y soportes del tipo D.II de la tipología de Ruiz Mata (1995). A la Primera Edad del Hierro también pertenecen formas cerámicas con paralelos en la meseta, como las cazuelas y los vasos troncocónicos que definen respectivamente las formas III.A y VI de Blasco et al. (1991), además de la cerámica pintada bícroma estilo Meseta (Miguel 2020). Sin embargo, también existen formas cerámicas tradicionalmente adscritas a los momentos precedentes del Bronce Final como las cazuelas A.I.a, las ollas G.I., los vasos E.I.b o las cazuelas A.I-II de la tipología de Ruiz Mata (1995). Algunos de estos tipos tuvieron proporciones destacadas dentro de sus grupos, como es el caso de las cazuelas A.I.a con respecto a las A.II. No obstante, los grandes porcentajes de cuencos B.II señalan a estas cazuelas de carena alta marcada como perduraciones o elementos residuales.

Por tanto, y como ocurría en el C-23 del Sector IV de Alarcos (Fernández Rodríguez 2012: 60), nos hallamos ante un contexto material típico de la Primera Edad del Hierro en el que pervivieron elementos anteriores. Una situación análoga se constata en los niveles correspondientes a la transición Bronce Final-Hierro I del cerro de las Cabezas, en el que las cerámicas a mano pintadas 
estilo Medellín (Esteban et al. 2003: fig. 6, 3-5), típicas de la Primera Edad del Hierro, convivieron con cazuelas A.I.a (Esteban et al. 2003: fig. 6, 10-11). Llama la atención que en este contexto transicional del Bronce Final a la Primera Edad del Hierro en el Alto Guadiana no se constate cerámica a torno, sobre todo si se tienen en cuenta las incuestionables relaciones con el SO peninsular donde se estaban desarrollando producciones a torno tartésicas y coloniales a causa de la presencia estable fenicia desde finales del s. IX cal. a.C. (Torres 2008b: 139). Esta circunstancia plantea la posibilidad de que dichas producciones a torno no entraran dentro de los gustos o las concepciones locales, explicando la causa por la que no fueron adquiridas ni producidas por las comunidades del Alto Guadiana. Estos contextos, en los que se documentan materiales de la Primera Edad del Hierro con perduraciones anteriores y con una total ausencia de cerámica a torno, se repite tanto en el Alto Guadiana, caso del estrato 13 del corte A1 (ab) de La Bienvenida-Sisapo (Fernández Ochoa et al. 1994) o Alarcos, como en el Bajo Guadiana, caso de Monte do Bolor 3 (Antunes et al. 2017: 166). Lo mismo ocurre en la Meseta donde se ha diferenciado un Hierro Antiguo o Hierro I con la práctica inexistencia de cerámica a torno (Blasco et al. 1991). Esta progresiva introducción de los elementos coloniales en el valle del Guadiana estaría relacionada con su localización geográfica y las dinámicas culturales del momento, diferentes a las del Bajo Guadalquivir donde la interacción entre las poblaciones locales y fenicias fue mucho más estrecha e intensa.

En lo referente a la cronología, el conjunto cerámico y los paralelos señalados indican un periodo que se centra entre finales del s. IX y durante todo el s. VIII a.C., aunque existen recipientes cuyos paralelos se estratifican en contextos más recientes. La cronología radiocarbónica de las muestras analizadas de estos niveles oscilan entre finales del s. X cal. a.C. y el 750 cal. a.C. (fig. 10). Sin embargo, si se atiende exclusivamente a las muestras de vida corta (Beta-475572, Beta-513968), los intervalos de probabilidad se concentran fundamentalmente en el periodo comprendido entre el 850 y el 750 cal. a.C. Es posible que los resultados de la muestra de carbón (Beta-473984) muestren una cronología más antigua a la del contexto, quizás por estar sometida al efecto de "madera vieja", ya que el hueso analizado (Beta-475572) en el mismo nivel presenta una cronología más reciente que no llega al s. X cal. a.C. como la primera. Las fechas obtenidas del nivel 1 del C-23 de Alarcos comparten este espacio cronológico (Fernández Rodríguez 2012: tab. 1), así como las de Setefilla donde se halló un vaso à chardon similar al de Alarcos (Barndherm y Krueger 2017: fig. 6). La fase V de El Carambolo, en la que también se han apuntado algunos paralelos, se fecharía a finales del s. IX o principios del s. VIII cal. a.C. según la cronología que arrojan los niveles fundacionales (Fernández Flores y Rodríguez Azogue 2007: fig. 14).

Por tanto, considerando la cronología que aportan los materiales y las muestras analizadas por radiocarbono, los niveles de Alarcos exhumados en 2017 y los materiales asociados se fecharían en torno a mediados del s. VIII a.C. o un poco antes, por lo que durante los últimos años de la transición Bronce Final-Hierro I o los primeros años de la Primera Edad del Hierro. Sin embargo, si se atiende exclusivamente a la cronología radiocarbónica, el contexto estudiado comprendería los momentos finales del s. IX y toda la primera mitad del s. VIII cal a.C., por lo que dentro de lo que se ha denominado como período transicional Bronce Final-Hierro I.

Esta etapa se caracterizó por una estrecha vinculación con la cultura tartésica, por lo que, como se viene aceptando desde los años setenta del s. XX para el Guadiana medio (Almagro 1977; Rodríguez González 2018) y como se viene reivindicando desde los años noventa para el cercano yacimiento de La Bienvenida-Sisapo (Fernández Ochoa et al. 1994: 144-145; Zarzalejos et al. 2017: 60; Esteban et al. 2019: 80, nota 2), es muy posible que Alarcos se deba integrar en los límites en los que la cultura tartésica ejerció una gran influencia, sobre todo si las recientes investigaciones han considerado el espacio

\begin{tabular}{|c|c|c|c|c|c|c|}
\hline Contexto & Muestra & Referencia & Fecha BP & Ratio & Cal BC 1 sigma & Cal BC 2 sigma \\
\hline AL17-U18-3-3 & Carbón & Beta-473984 & $2700 \pm 30 \mathrm{BP}$ & -25.0 & $905-806 \mathrm{AC}$ & $851-813 \mathrm{AC}$ \\
\hline AL17-U18-2-4 & Hueso & Beta-513968 & $2640 \pm 30 \mathrm{BP}$ & -20.6 & $846-789 \mathrm{AC}$ & $893-876 \mathrm{AC}$ \\
\hline AL17-U18-3-3 & Hueso & Beta-475572 & $2530 \pm 30 \mathrm{BP}$ & -21.1 & $797-731 \mathrm{AC}$ & $791-750 \mathrm{AC}$ \\
\hline
\end{tabular}

Fig. 10: Dataciones radiocarbónicas (a partir de García Huerta et al. 2020: tabla 12). 
situado algo más al $\mathrm{N}$ de la línea del Guadiana como el límite para el desarrollo de la misma (Rodríguez González 2018: fig. 1). De esta forma, la zona correspondiente al Alto Guadiana quedaría inserta en el fenómeno de la cultura tartésica, aunque con diferencias con respecto a la zona nuclear del Bajo Guadalquivir, ya que esta región contaría con sus propias dinámicas culturales y redes de contacto que le ofrecerían una personalidad propia dentro del espacio geográfico que delimita a Tarteso.

En el caso particular de Alarcos, aunque sería extensible a todo el Alto Guadiana, parece que, en un primer momento, correspondiente a la transición Bronce FinalHierro I que se fecharía poco antes de mediados del s. VIII a.C., determinados aspectos que se estaban desarrollando entre las poblaciones tartésicas del Bajo Guadalquivir, como la citada cerámica a torno, no fueron del gusto o no entroncaron con las concepciones de estas comunidades del Alto Guadiana. Sin embargo, las producciones cerámicas a mano de dichas comunidades fueron exactamente las mismas a las producidas por las poblaciones tartésicas de la zona nuclear en el Bajo Guadalquivir, tanto en formas como en decoración. Esta circunstancia tendría que ver con los propios gustos, ya que tanto la tecnología a mano, como las cocciones reductoras, las superficies oscuras y bruñidas o las formas carenadas estarían acordes con las tradiciones y con las producciones que se estaban desarrollando hasta ese momento en la meseta S. Así, las similitudes entre la cultura material del Alto Guadiana y la del Bajo Guadalquivir se establecieron, en un primer momento, a través de las producciones a mano típicamente tartésicas, como el repertorio de formas estudiado en este trabajo. Sin embargo, y reiterando la idea anterior, la posición geográfica de Alarcos favoreció el contacto con otras regiones geográficas, por lo que, dentro de un ambiente cultural de tinte fundamentalmente tartésico, existieron elementos culturales diferenciadores en el Alto Guadiana que no aparecen en la zona nuclear de Tarteso, como la cerámica bícroma estilo Meseta o todas aquellas cerámicas a mano con paralelos en la meseta o la Alta Andalucía.

Posteriormente, en pleno Hierro I, se documentan cambios más drásticos en el Alto Guadiana. Dichos cambios se materializan en el desarrollo de una arquitectura de filiación tartésica o una producción cerámica a torno que reinterpreta tipos y estilos tartésicos o fenicios, como la cerámica de barniz rojo, la cerámica gris o la cerámica bícroma a torno entre otras (Zarzalejos y López 2005), además de la introducción del rito incinerador como constata la necrópolis del Sector IV-E de Alarcos (Fernández Rodríguez 2001) o la necrópolis de Los Cotos (Alhambra, Ciudad Real) (Benítez de Lugo y Fuentes 2021), si bien la incineración en el vaso bicónico con incrustaciones metálicas del sector IV-E de Alarcos parece ser anterior y, como consecuencia, indicaría el inicio del desarrollo de la incineración en un período que se adscribiría a la transición Bronce Final-Hierro I. En esta época también se adquirieron algunas importaciones griegas o fenicias, como constata un fragmento de kotýle protocorintia y el borde de ánfora fenicia del tipo T.10.1.2.1 del área 4 de la Bienvenida-Sisapo (Zarzalejos et al. 2017: figs. 14; 15, 6), así como la cerámica de barniz rojo y la copa jonia del tipo B2 de los niveles 11a y 12a del corte A1 (ab) de este mismo yacimiento (Fernández Ochoa et al. 1994: fig. 98, 1), una cerámica de barniz rojo fenicia que también se registra en el nivel 4 del C-23 de Alarcos (Fernández Rodríguez 2012: 46).

Por tanto, se podría defender, según la documentación expuesta, la inclusión plena de Alarcos en particular y del Alto Guadiana en general en la órbita de la cultura tartésica, aunque se trata de un espacio con elementos propios que lo diferencian de otras regiones en las que se desarrolló el mismo fenómeno cultural y que se explican por el propio sustrato local o los contactos comerciales y culturales entre el Alto Guadiana y otras regiones geográficas, como la meseta o la Alta Andalucía.

\section{AGRADECIMIENTOS}

Mi más sincero agradecimiento al equipo de investigación del área de Prehistoria de la Universidad de Castilla-La Mancha, dirigido por la Dra. Dña. M. del Rosario García Huerta, por haberme permitido el estudio y publicación de los materiales del Sector III de Alarcos.

\section{BIBLIOGRAFÍA}

ALMAGRO, M. (1977): El Bronce Final y el Periodo Orientalizante en Extremadura, Madrid.

ALMAGRO, M.; TORRES, M. (2008): Cerámica a mano, La necrópolis de Medellín. II. Estudio de los hallazgos (M. Almagro, dir.), Madrid, 734-748

ANTUNES, A. S.; DE DEUS, M.; MONGE SOARES, A.; SANTOS, F.; ARÊZ, L.; DEWULF, J.; BAPTISTA, L.; OLIVEIRA, L. (2012): Povoados abertos do Bronze Final do Médio Guadiana, Sidereum Ana II. El río Guadiana en el Bronce Final (J. Jiménez ed.), Mérida, 277-308. 
ANTUNES, A. S.; DE DEUS, M.; ESTELA, S.; LARRAZABAL, J.; MONGE SOARES, R.; SALVADOR MATEOS, R. M. (2017): Monte do Bolor 3, Monte do Pombal 2, Salsa 3 e Torre Velha 3: contextos de planicie da I Idade do Ferro do Alentejo interior, Sidereum Ana III. El río Guadiana y Tartessos (J. Jiménez ed.), Mérida, 159-185.

ARRUDA, A. M.; DE OLIVEIRA, C. F.; TEIXEIRA, V. (2017): Castro Marim entre indígenas, fenícios e tartéssicos, Sidereum Ana III. El río Guadiana y Tartessos (J. Jiménez ed.), Mérida, 443-466.

AUBET, M. E.; SERNA, M. R.; ESCACENA J. L.; RUIZ DELGADO, M. M. (1983): La Mesa de Setefilla. Lora del Río (Sevilla). Campaña de 1979, Madrid.

BENÍTEZ DE LUGO, L. (2004): Conclusiones y valoración final 1998-2000, Mentesa Oretana 1998-2002 (L. Benítez de Lugo, dir.), Ciudad Real, 269-274.

BENÍTEZ DE LUGO, L.; FUENTES, J. L. (2021): Representaciones del poder en ámbitos funerarios de la Oretania septentrional: el reflejo del poder en la muerte, La Cámara sepulcral de Toya (1918-2018), cien años de nvestigaciones, Jaén.

BLASCO, M. C.; LUCAS, R.; ALONSO, A. (1991): Excavaciones en el poblado de la Primera Edad del Hierro del Cerro de San Antonio (Madrid), Arqueología, paleontología y etnografía, Madrid, 9-159.

BRANDHERM, D.; KRUEGER, M. (2017): Primeras determinaciones radiocarbónicas de la necrópolis de Setefilla (Lora del Río) y el inicio del periodo orientalizante en Andalucía occidental, TP 74 (2), 296-318

DOI: https://doi.org/10.3989/tp.2017.12196

CASADO, M. (2015): La cerámica con decoración geométrica del Carambolo, Sevilla.

ESTEBAN, G.; HEVIA, P.; PÉREZ AVILÉS, J. J.; VÉLEZ, J. (2003): La transición del Bronce Final a la Primera Edad del Hierro en el Cerro de las Cabezas (Valdepeñas, Ciudad Real), Cuadernos de Estudios Manchegos 24-25, 10-46.

ESTEBAN, G.; ZARZALEJOS, M.; HEVIA, P. (2019): Cerámicas a mano pintadas de Sisapo-La Bienvenida (Almodóvar del Campo, Ciudad Real), Las cerámicas a mano pintadas postcocción de la península ibérica durante la transición entre el Bronce Final y la I Edad del Hierro (E. Rodríguez González, S. Celestino eds.), Mérida, 75-109.

FERNÁNDEZ FLORES, A.; RODRÍGUEZ AZOGUE, A. (2007): Tartessos desvelado. La colonización fenicia del suroeste peninsular y el origen y ocaso de Tartessos, Córdoba.

FERNÁNDEZ OCHOA, C.; ZARZALEJOS, M.; HEVIA, P.; ESTEBAN, G. (1994): Sisapo I. Excavaciones arqueológicas en "La Bienvenida”, Almodóvar del Campo (Ciudad Real), Toledo.

FERNÁNDEZ RODRÍGUEZ, M. (2001): La necrópolis del Sector IV-E de Alarcos, Arqueología funeraria. Las necrópolis de incineración (M. R. García Huerta, F. J. Morales, coords.), Cuenca, 259-284.
FERNÁNDEZ RODRÍGUEZ, M. (2012): Apuntes sobre el Bronce Final y la Primera Edad del Hierro en Alarcos (Ciudad Real), Sidereum Ana II. El río Guadiana en el Bronce Final (J. Jiménez ed.), Mérida, 41-64.

FERRER, E.; RUIZ CECILIA J. I.; GARCÍA FERNÁNDEZ, F. J. (2017): Nuevos datos sobre el Bronce Final en Osuna, $T e$ rritorios comparados: Los valles del Guadalquivir, el Tajo y el Guadiana en época tartésica (S. Celestino; E. Rodríguez González eds.), Mérida, 79-119.

FIGUEIREDO, M.; MATALOTO, R. (2017): Necrópoles rurais sidéricas do Baixo Alentejo setentrional: sociedade e mundo funerário nos Barros de Beja, Sidereum Ana III. El río Guadiana y Tartessos (J. Jiménez ed.), Mérida, 353-398.

GARCÍA HUERTA, M. R. (2019): Las cerámicas postcocción de la Meseta Sur: El ejemplo de Alarcos (Ciudad Real), Las cerámicas a mano pintadas postcocción de la península ibérica durante la transición entre el Bronce Final y la I Edad del Hierro (E. Rodríguez González y S. Celestino, eds.), Mérida, 39-74.

GARCÍA HUERTA, M. R.; FERNÁNDEZ RODRÍGUEZ, M. (2000): La génesis del mundo ibérico en la submeseta sur: El tránsito del Bronce Final-I Edad del Hierro en Alarcos, CUPAUAM, 26, 47-68. DOI: https://doi.org/10.15366/cupauam2000.26.003

GARCÍA HUERTA, M. R.; MORALES, F. J. (2017): El poblado de Alarcos (Ciudad Real) en los inicios del I milenio a.C.: estructuras y materiales cerámicos, TP 74(1), 108-126. DOI: https://doi.org/10.3989/tp.2017.12186

GARCÍA HUERTA, M. R.; MORALES, F. J.; OCAÑA, A. (1999): El poblado de la Edad del Hierro de Peñarroya (Argamasilla de Alba, Ciudad Real), I Jornadas de Arqueología ibérica en Castilla-La Mancha (M. A. Valero, coord.), Toledo, 221-258.

GARCÍA HUERTA, M. R.; MORALES, F. J.; RODRÍGUEZ GONZÁLEZ, D. (2018): De la muerte a la eternidad: la necrópolis ibérica de Alarcos (Ciudad Real), Madrid.

GARCÍA HUERTA, M. R.; MORALES, F. J.; RODRÍGUEZ GONZÁLEZ, D. (2020): El Cerro de Alarcos (Ciudad Real): formación y desarrollo de un oppidum ibérico, Oxford.

GARRIDO, J. P.; ORTA, E. M. (1978): Excavaciones en la necrópolis de "La Joya" Huelva II (3 $3^{a}, 4^{a}$ y $5^{a}$ campañas $)$, Madrid.

GONZÁLEZ DE CANALES, F.; SERRANO PICHARDO, L.; LLOMPART, J. (2010): El inicio de la Edad del Hierro en el suroeste de la península ibérica, las navegaciones precoloniales y cuestiones en torno a las cerámicas de Huelva, IV Encuentro de Arqueología del Suroeste. Aracena (Huelva), 27-29 de noviembre de 2009 (J. A. Pérez Macías, E. Romero Bomba, eds.), Huelva, 648-697.

GONZÁLEZ PRATS, A. (1983): Estudio arqueológico del poblamiento antiguo de la sierra de Crevillente (Alicante), Alicante. 
HUNT, M. A.; GARCÍA RIVERO, D. (2017): El asentamiento protohistórico de Jardín de Alá (Salteras, Sevilla), Territorios comparados: Los valles del Guadalquivir, el Tajo y el Guadiana en época tartésica (S. Celestino, E. Rodríguez González eds.), Mérida, 47-77.

JIMÉNEZ, J.; HERAS, F. J. (2017): La ocupación orientalizante de la Escuela de Hostelería de Mérida, Sidereum Ana III. El río Guadiana y Tartessos (J. Jiménez ed.), Mérida, 107-129.

LECHUGA, M. A.; SOTO, M. (2017): La tumba de la mujer y el joven del cerro de los Vientos (Puente del Obispo, Baeza), La Dama, el Príncipe, el Héroe y la Diosa, Jaén, 9-17.

LÓPEZ ROA, C. (1977): La cerámica con decoración bruñida en el suroeste peninsular, TP 34, 341-370.

LUZÓN, J. M.; RUIZ MATA, D. (1973): Las raíces de Córdoba. Estratigrafía de la Colina de los Quemados, Córdoba.

MATALOTO, R. (2012): Os Sehnores e as Serras: o final da Idade do Bronze no Alentejo Central, Sidereum Ana II. El río Guadiana en el Bronce Final (J. Jiménez, ed.), Mérida, 185-213.

MIGUEL, P. (2019): Calatrava la Vieja (Carrión de Calatrava, Ciudad Real) durante la Primera Edad del Hierro (c. fin s. VIII550 a.C.), Spal, 28(1), 79-96.

DOI: https://doi.org/10.12795/spal.2019.i28.04

MIGUEL, P. (2020): Definición y caracterización de las cerámicas a mano con decoración pintada del sur de la península ibérica en época tartésica, Oxford.

MOLINA, F.; MENDOZA, A.; SAEZ, L.; ARTEAGA, O.; AGUAYO, P.; ROCA, M. (1983): Nuevas aportaciones para el estudio del origen de la cultura ibérica en la Alta Andalucía. La Campaña de 1980 en el cerro de los Infantes, XVI Congreso Nacional de Arqueología, Cartagena, 1982, Zaragoza, 689-708.

MONGE SOARES, R.; MONGE SOARES, A. M. (2017): O Cabeço Redondo (Moura). Um edificio monumental e singular na margen esquerda do Guadiana, Sidereum Ana III. El río Guadiana y Tartessos (J. Jiménez, ed.), Mérida, 421-441.

ORTA, E. M.; GARRIDO, J. P. (1963): La tumba orientalizante de «La Joya», Huelva, TP 11, 7-36.

PELLICER, M.; ESCACENA, J. L.; BENDALA, M. (1983): El cerro Macareno, Madrid.

PEREIRA, J. (2019): Las cerámicas pintadas del Tajo: el ejemplo de la Casa del Carpio (Toledo), Las cerámicas a mano pintadas postcocción de la península ibérica durante la transición entre el Bronce Final y la I Edad del Hierro (E. Rodríguez González, S. Celestino eds.), Mérida, 145-160.

PÉREZ AVILÉS, J. J.; VÉLEZ, J. (1996): Estudio sobre la Protohistoria de Valdepeñas y su comarca, Cuadernos de Estudios Manchegos 22, 9-37.
RODRÍGUEZ GONZÁLEZ, E. (2018): El poblamiento del valle medio del Guadiana durante la I Edad del Hierro, Madrid.

RUFETE, P. (2002): El final de Tartessos y el periodo turdetano en Huelva, Huelva.

RUIZ MATA, D. (1995): Las cerámicas del Bronce Final. Un soporte tipológico para delimitar el espacio y el tiempo tartésico", Tartessos, 25 años después (1968-1993). Actas del Congreso Conmemorativo del V Symposium Internacional de Prehistoria Peninsular, Cádiz, 265-313.

RUIZ MATA, D., BLÁZQUEZ, J. M.; MARTÍN DE LA CRUZ, J. C. (1981): Excavaciones en el Cabezo de San Pedro (Huelva). Campaña de 1978, Huelva Arqueológica 5, 149-316.

RUIZ MATA, D.; FERNÁNDEZ JURADO, J. (1986): El yacimiento metalúrgico de época tartésica de San Bartolomé de Almonte (Huelva), Huelva.

SANTOS, F.; ANTUNES, S.; DE DEUS, M.; GRILO, C. (2017): A Necrópole de Palhais (Beringel, Beja), Sidereum Ana III. El río Guadiana y Tartessos (J. Jiménez ed.), Mérida, 227-261.

TORRES, M. (2008a): Vasos «a Chardón», La necrópolis de Medellín. II. Estudio de los hallazgos (M. Almagro dir.), Madrid, 658-662.

TORRES, M. (2008b): The Chronology of the Late Bronze Age in Western Iberia and the beginning of the Phoenician colonization in the Western Mediterranean, A new Dawn for the Dark Age? Shifting Paradigms in Mediterranean Iron Age Chronology, Oxford: 135-147.

VALENCIANO, M. C.; POLO, J. (2010): Una necrópolis del Hierro en Atalaya del Cañavate, Cuenca: La Cañada del Santo, Actas de las II Jornadas de Arqueología de Castilla-La Mancha (A. Madrigal, M. R. Perlines, coords), Toledo, 344-367.

VÉLEZ, J.; PÉREZ AVILÉS, J. J. (1999): Oretanos en la meseta sur. El yacimiento ibérico del cerro de las Cabezas (Valdepeñas), Revista de Arqueología 20 (213), 46-55.

ZARZALEJOS, M.; LÓPEZ, J. (2005): Apuntes para una caracterización de los procesos orientalizantes en la Meseta Sur, $E l$ periodo Orientalizante (S. Celestino, J. Jiménez, eds.), Mérida, 809-842.

ZARZALEJOS, M.; ESTEBAN, G.; HEVIA, P. (2012): El Bronce Final en el Alto Guadiana. Viejos y nuevos datos para una lectura histórica, Sidereum Ana II. El río Guadiana en el Bronce Final (J. Jiménez, ed.), Mérida, 15-40.

ZARZAleJos, M.; ESTEBAN, G.; HEVIA, P. (2017): El Alto Guadiana entre los siglos VIII y VI a.C. Novedades estratigráficas en el Área 4 de Sisapo-La Bienvenida (Almodóvar del Campo, Ciudad Real), Sidereum Ana III. El río Guadiana y Tartessos (J. Jiménez, ed.), Mérida, 39-67. 